\title{
FATORES QUE AFETAM A FIXAÇÃO DE FOSFATOS NOS SOLOS DO ESTADO DE SÃO PAULO
}

\author{
MARA REGINA DOS S. RODRIGUES
}

Engenheiro Agrònomo

Orientador: Dr. Francisco de Assis Ferraz de Mello

Dissertação apresentada à Escola Superior de Agricultura "Luiz de Queiroz", da Universidade de São Paulo, para obłençāo do título de Mestre em Solos e Nutrição de Plantas.

$P|R A C| C A B A$

Estado de São Paulo - Brasil

Março, 1980 
A minha mãe

"IN MEMORIAM"

A meu pai, irmãs e sobrinho DEDICO 


\section{AGRADEC IMENTOS}

Ao Prof. Dr. Francisco de Assis Ferraz de Mello, pela orientação.

Ao Prof. Dr. Octāvio Freire pelas sugestões.

Aos Engọs. Agrọs Roza Maria Schunke e Marta Elena Gonzalez Mendes pela colaboração e amizade.

Aos funcionārios do Departamento de Solos da ESALQ pela ajuda no decorrer das anālises quỉmicas e físicas preliminares.

Ao PICD/CAPES/UFPEL pela concessão de Bolsa de Pós-graduação.

A todos aqueles que direta ou indiretamente colaboraram na realização deste trabalho. 
INDICE

Pāgina

LISTA DE QUADROS $\ldots \ldots \ldots \ldots \ldots \ldots \ldots \ldots \ldots \ldots \ldots \ldots \ldots \ldots \ldots \ldots \ldots \ldots \ldots \ldots \ldots$

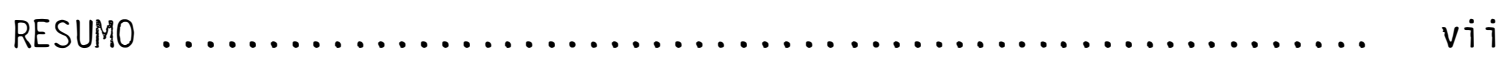

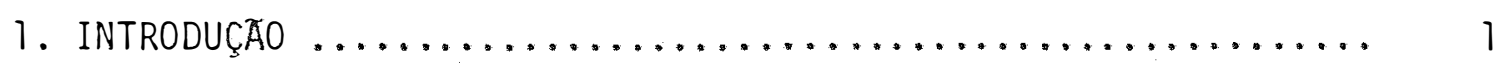

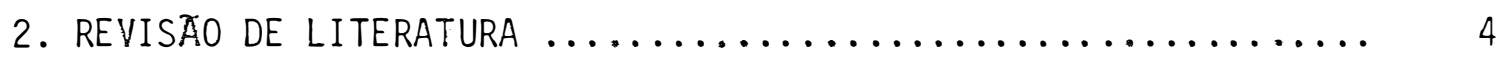

2.1. Considerações Gerais Sobre o Termo Fixação ........... 4

2.2. Fatores que Afetam a Fixação de Fösforo $\ldots . . . . . . . . . .5$

2.2.1. Infiuência das argilas $\ldots \ldots \ldots \ldots \ldots \ldots \ldots \ldots$. 6

2.2.2. Influência do Cálcio e Magnésio ............... 8

2.2.3. Influência da matéria orgänica $\ldots \ldots \ldots \ldots \ldots \ldots .10$

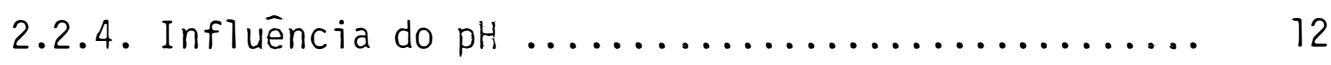

2.2.5. Influência do alumīnio trocāvel ............ 14

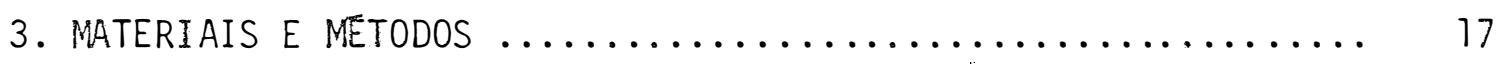

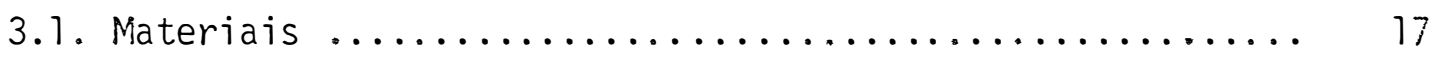

3.2. Determinação das caracterîsticas físicas e quîmicas $\ldots . . \quad 17$

3.2.1. Caracterização física $\ldots \ldots \ldots \ldots \ldots \ldots \ldots \ldots . .28$

3.2.2. Caracterização quîmica .................. 28

3.3. Determinação da capacidade de fixação de fosfato pelo solo ............................. 30

3.3.1. Marcha de determinação ................. 30

3.3.2. Cálculo da porcentagem de fosfato fixado ....... 30

4. RESULTADOS E DISCUSSAO .......................... 32

4.7. Influencia do pH na porcentagem de fosfato fixado ..... 38 
4.2. Influência da $\%$ de carbono na porcentagem de fixação de fosfato .............................. 38

4.3. Influência do $P$ solūvel na capacidade de fixação de fosfatos ............................. 39

4.4. Influência do Ca e $\mathrm{Mg}$ trocáveis sobre a capacidade de fixação de fosfatos $\ldots \ldots \ldots \ldots \ldots \ldots \ldots \ldots \ldots . . \ldots \ldots$

4.5. Influência do $\mathrm{Al}^{+3}$ trocável sobre a capacidade de fixação de fosfatos ........................ 40

4.6. Influência da capacidade de troca de cations (C.T.C.) sobre a capacidade de fixação de fosfatos ........... 41

4.7. Influência da soma de bases trocáveis na capacidade

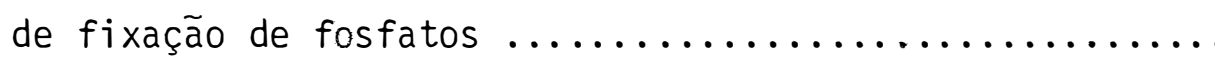

4.8. Influéncia do teor de argila na capacidade de fixa-

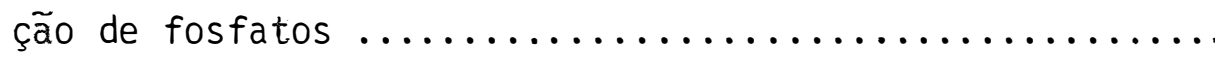

4.9. Influência do teor de Areia Total na capacidade de

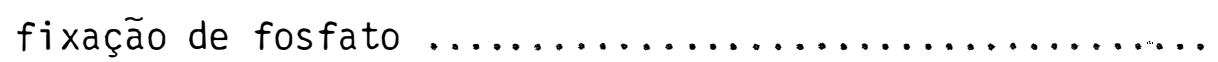

4.10. Influência do teor de limo na capacidade de fixação

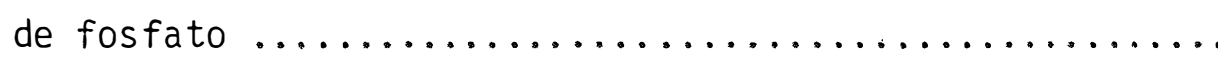

4.11.Correlação linear mūltipla entre a capacidade de fi xação de fosfato e as características do solo estu-

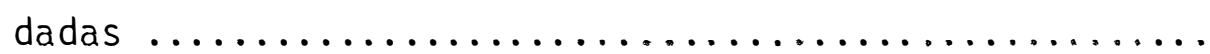

5. CONCLUSOES .................................... 46

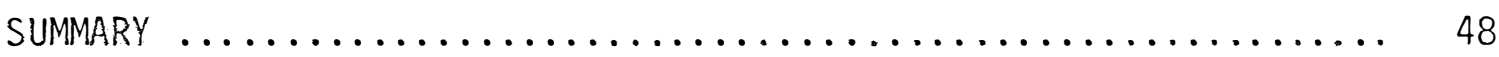

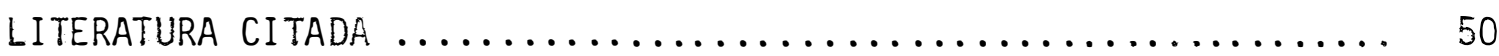




\section{LISTA DE QUADROS}

Quadro no

Página

1 Resultados da anālise granulomētrica das 100 amostras

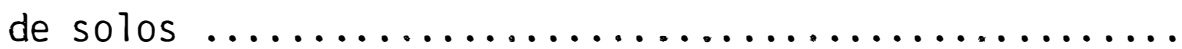

2 Resultados da anālise quĩmica das 100 amostras de solos.

3 Resultados do ensaio de fixação de fosfato $\ldots . . . . . .$.

4 Correlação entre a porcentagem de fósforo fixado e as características do solo consideradas ...............

5 Anālise de variāncia final de regressão 1 inear mūltipla para Y (\% de fósforo fixado) e as variāveis selecionadas $\mathrm{X}_{2}$ (\% de carbono) $\mathrm{X}_{4}\left(\mathrm{Mg}^{++}\right.$trocāvel) e $X_{5}(A)^{+3}$ trocāvel $)$ e $x_{9}(\%$ de argila $\ldots \ldots \ldots \ldots .44$ 
RESUMO

Foi conduzido um experimento em laboratōrio, utilizando-se 100 amostras de solo oriundas de diferentes localidades do Estado de São Paulo, visando verificar a influēncia de caracterīsticas quīmicas e físicas do solo sobre a capacidade de fixação de fosfatos das mesmas.

As amostras de solo foram submetidas preliminarmente à anāilise quỉmica e granulomëtrica e, posteriormente, ao teste para avaliação da capacidade de fixação de fosfatos.

Os resultados encontrados foram analizados estatisticamente atravēs de correlações lineares simples e correlação linear mūltipla, resultando as seguintes conclusões:

1. Com base na anālise de regressão linear simples as caracteristicas do solo que afetaram significativamente a capacidade de fixação de fosfato dos solos do estado de São Paulo foram: porcentagem de carbono, teor de $\mathrm{Al}^{+3}$ trocável, C.T.C. porcentagem de argila, pH e porcentagem de areia. 
2. Com base na anālise de regressão linear mūltipla as cá racterīsticas que mais influenciaram a capacidade de fixação de fosfato dos solos do Estado de São Paulo foram: porcentagem de carbono, teor de $\mathrm{Mg}^{+2}$ trocāvel, teor de $\mathrm{Al}^{+3}$ trocāvel e porcentagem de argila.

3. A equação que melhor exprime o fenômeno de fixação de fosfatos para solos do Estado de São Paulo pode ser assim expressa:

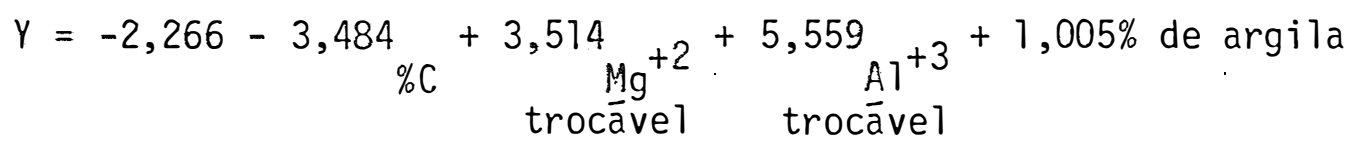

4. O fenômeno de fixação de fosfatos pelo solo está sob influência do efeito conjunto das caracterîsticas físicas e quĩmicas do solo sobre o processo. 
1. INTRODUÇAOO

Embora a quantidade de fósforo total num solo mineral médio corresponda à do nitrogénio, é muito menor do que a do potássio, do cálcio ou do magnésio. Assume importāncia ainda maior o fato da maioria do fósforo existente nos solos não ser assimilável pelos vegetais. Além disso quando são adicionadas aos solos quantidades solūveis deste elemen to na forma de fertilizantes o seu fósforo é muitas vezes fixado ou tornado inassimilāvel, mesmo sob condições ideais.

As prāticas de adubação em muitas āreas exemplificam muito bem o problema da disponibilidade do fọ́sforo. A necessidade de elevar doses de fertilizantes, quando estão sendo removidas quantidades relativamente pequenas de fósforo, indica que grande parte dos fosfatos adicionados se tornam indisponiveis para os vegetais em crescimento.

Segundo HEMWALL (1957), somente 10 a $30 \%$ dos fosfatos soIūveis aplicados como fertilizantes são recuperados pelas plantas, o res tante, 70 a $90 \%$ resulta fixado na fase sōlida do solo. 
A fixação do fosfato solūvel pelo solo é um fenōmeno de importante significado agrícola. Embora seja de natureza complexa e ain da não bem compreendida, numerosas teorias tem sido propostas para explicā-la.

Nos solos ácidos julgam-se que as principais causas de fixação do $P$ sejam a formação de compostos insolūveis com $\mathrm{Fe}, \mathrm{Al}, \mathrm{Ti}, \mathrm{Mn}$, etc., a adsorção aos óxidos hidratados desses metais e aos minerais de argila.

Nos terrenos alcalinos as principais causas da fixação se riam a formação de fosfatos de cálcio insolūveis a adsorção do fosfato às partỉculas de carbonato de cálcio e a retenção pelas argilas.

Acredita-se que, para as condições gerais dos solos do Estado de São Paulo, a principal causa da fixação do fosfato é a adsorção à superfície das partīculas coloidais de óxidos hidratados de ferro, aluminio e outros (MELLO, 1968).

Nem todos os solos apresentam uma mesma capacidade para fixar o fósforo. Dependendo da natureza de seus constituintes e até certo ponto dos processos e fatores envolvidos um dado solo poderā reter uma quantidade de fósforo vārias vēzes superior à fixada por um outro.

Tendo em vista que a quantidade de fósforo fixada por um solo depende de uma série de características físicas e quîmicas do mesmo, o presente trabalho tem como objetivo verificar a influência de alguns fatores como ph, percentagem de carbono, teores de argila, limo, 
areia, Ca, Mg, Al, trocāveis e de $P$ solūvel sobre a fixação de fosfato por amostras de solos do Estado de São Paulo.

Para atingir esse objetivo tais amostras foram submetidas à anālises quỉmica e granulometrica e a um teste de capacidade de fixação de fosfatos. As quantidades fixadas foram correlacionadas com as ca racteristicas dos solos mencionadas. 
2. REVISÃO DE LITERATURA

2.1. Considerações Gerais Sobre o Termo Fixação.

0 fenōmeno de fixação foi observado inicialmente, segundo HEMWALL (1957), na Europa ao redor de 1850, mas os maiores progressos para o seu esclarecimento se deram a partir de 1930.

KARDOS (1969) define genericamente o termo fixação como sendo o processo através do qual nutrientes prontamente solūveis são transformados em formas menos solūveis atravēs da reação com os componen tes orgānicos e inorgānicos do solo restringindo a sua mobilidade no so10 e diminuindo a sua disponibilidade às plantas.

Segundo CATANi e PELLEGRINO (1960), fixação ē um termo empregado para traduzir a transformação de formas solūveis de fósforo em outras formas menos solūveis. Qualquer fenōmeno que determine um decréscimo na concentração do ion ortofosfato de uma solução em contato com o solo é responsāvel pela fixação.

Diversos dados experimentais parecem indicar que a fixação do ion fosfato não constitui necessariamente perda de disponibilidade 
às plantas (CATANI, 1947; MENDES, 1950). Constituiria, então, um importante mecanismo de proteção do fósforo contra as perdas atravēs das águas de percolação.

\subsection{Fatores que Afetam a Fixação de Fósforo}

Grande quantidade de trabalhos indica que a fixação de fósforo pelo solo apresenta correlações com vārias caracterīsticas do so 10, tais como, matéria orgânica, argila e alumīnio trocāvel ou extraível (AHENKORAH, 1968; FASSBENDER, 1966; HEMWALL, 1957).

BRADFIELD et alii (1935) propuseram a seguinte explicação para os mecanismos envolvidos na fixação do fósforo no solo:

a. Na faixa de pH entre 2,0 à 5,0 a fixação é devida prin cipalmente, à precipitação do fósforo por ions de ferro e alumínio que resultam na solução do solo apōs gradual dissolução dos óxidos destes elementos;

b. Na faixa de pH de 4,5 à 7,5 os fosfatos são fixados na superfície das particulas de argila (sesquióxidos hidratados e argilas silicatadas);

c. Na faixa de $\mathrm{pH}$ de 6,0 à 10 , os fosfatos são precipitados por cations divalentes porventura presentes na solução do solo.

De acordo com TISDALE e NELSON (1965), os principais fatores que afetam a fixação de fósforo são os seguintes: tipo de mineral de argila, tempo de reação, pH, temperatura, matēria orgânica, saturação de fósforo no solo e relação $\mathrm{R}_{2} \mathrm{O}_{3} / \mathrm{P}_{2} \mathrm{O}_{5}$. 


\subsubsection{Influência das argilas}

ANASTACIO (1968) estudando a capacidade de fixação de

fosforo em solos brasileiros concluiu que dentre as caracteristicas do solo o teor de argila tem uma influência relativa na fixação de fósforo. Amostras com teores de argila de $22 \%$ fixaram $22 \%$ e as amostras com teor de argila de $18 \%$ fixaram $20 \%$.

COLLEMAN (1944) investigou a influência da textura das argilas caulinita e montmorilonita na fixação do fósforo em solos dos Es tados Unidos. Observou que quase a totalidade do fósforo fixado pelas frações grosseiras $(0,2$ a 2,0 micra) e fina (menor que 0,2 micra) destes minerais era devido ao capeamento de óxidos livres de ferro e aluminio que os envolve. 0 autor concluiu que a fixação do fósforo $\vec{e}$, indubitavelmente, devido à troca aniōnica entre os ions fosfatos e as oxidrilas do capeamento de hidroxidos livres de ferro e aluminio dificilmente removiveis das argilas.

JUO e FOX (1977) estudando as características de adsorção de fosfatos em solos do oeste da Africa encontrou relação entre o conteüdo de argila, óxidos de ferro livre e os teores de fósforo dos solos es tudados.

As verificações de HASEMAN et alii (1950) quanto a fixação de fósforo pelas argilas caulinita, ilita, e montmorilonita indicaram aumento com a elevação da temperatura, com o aumento da concentração de fosfatos na solução e com a diminuição do pH. Sugerem a ocorrēncia de dois estāgios no processo de fixação: 
a. Uma fixação rāpida resultante da reação do fosfato com o alumīnio e/ou ferro prontamente disponîveis;

b. Uma fixação mais lenta resultante da reação do fosfato com aluminino e ferro liberados quando da decomposição das argilas acima citadas.

HALL e BAKER (1971) apresentam resultados interessantes sobre a importância do tipo de argila na retenção do fósforo em função do $\mathrm{pH}$. Esses autores constataram que a montmoritonita contribui para aumentar a quantidade de fósforo fixada pelo solo quando o $\mathrm{pH}$ se eleva, enquanto a quantidade fixada pela vermiculita diminui com o aumento do $\mathrm{pH}$.

Os solos argilosos requerem uma maior quantidade de fosfa to devido sobretudo, a sua elevada capacidade de fixação. Dentre os argilo-minerais os do grupo da vermiculita parecem apresentar maior poder de fixação. Além desse aspecto os argilo-minerais concorrem para uma maior fixação pela liberação do alumĩnio (COLE e JACKSON, 1950).

Argilo-minerais que possuem grupos $\mathrm{OH}^{-}$são capazes de reter ions fosfato. MILLAR (1955) adianta que tal processo ocorre principalmente na superfīcie desses minerais, sem excluir a possibilidade de tais minerais penetrarem entre as suas unidades básicas. Os que concordam que a troca de anions seja responsāvel pela remoção do fósforo solūvel da solução do solo apontam os átomos de ferro e alumînio expostos da rede cristalina como responsāveis pela retenção do fósforo (BASS e SIELING, 1950). 
CATANI e PELLEGRINO (1960), apresentaram dados relacionados com a fixação do fósforo em 15 solos do Estado de São Paulo ricos em óxidos hidratados de ferro e aluminio (terra roxa e roxa misturada). Os valores obtidos para a fixação foram em geral elevados e variaram de 3,5 a 24,0 e.mg de $\mathrm{PO}_{4}^{3-} / 100 \mathrm{~g}$ de solo. 0 solo que mais fixou fósforo apresentou o menor pH, o menor indice de saturação de bases e a maior porcentagem de argila; o menor valor para a fixação foi revelado por um solo muito ācido, com baixa saturação em bases, mas com uma baixa porcen tagem de argila.

MELLO (1968), verificou a capacidade de fixação de fosfato de alguns solos do Municīpio de Piracicaba, concluindo haver correlação entre a capacidade de fixação de fosfato das terras estudadas e os seus respectivos teores de limo e de argila.

\subsubsection{Influência do Cálcio e Magnēsio}

BUCKMAN \& BRADY (1967), consideram que a fixação de fósforo em solos alcalinos é provocada em parte, pelos compostos de cálcio, alēm da formação de precipitados.

Para CALVERT et alii (1960), a fixação do fósforo em qual quer solo varia de acordo com cations ativos presentes no sistema. No caso da presença de alumīnio e cálcio, a intensidade da fixação decresce nessa mesma ordem. Verificaram que a fixação do fósforo por argilas pre viamente acidificadas aumenta com a saturação de cálcio devido à formação de fosfatos de cálcio complexos tal como proposto por ELLIS e 
TRUOG (1955).

ALLISON (1943), trabalhando com solos podsōlicos de India na (USA) concluiu que as argilas saturadas com cālcio fixam muito mais fósforo do que aquelas saturadas com sōdio, na faixa de pH acima de 4,0, verificou que os ions cálcio aumentaram enormemente a retenção de fosfato pelas argilas. O fenōmeno foi explicado admitindo-se que o cálcio forma uma ligação com o ion $\mathrm{H}_{2} \mathrm{PO}_{4}$ e a micela coloidal. Uma outra explicação é dada por ELLIS e TRUDG (1955) que concluiram que no caso de saturação com cálcio e fixação não se deve à ligação $\mathrm{H}_{2} \mathrm{PO}_{4}$ - Cálcio- micela como concluiu o autor citado acima e sim, devido a formação de fosfatos complexos sobre as superfícies saturadas.

RAGLAND e SEAY (1957), estudaram o efeito do cálcio trocável sobre a fixação do fósforo pela fração argila de quatro solos podzölicos de Kentucky (USA). Verificaram que nas argilas previamente aci dificadas a fixação do fósforo aumentou quando a saturação do cálcio cres ceu além de $60 \%$. Admi tem que a retenção do fósforo foi devida a formação de fosfatos de cálcio e à ligação $\mathrm{H}_{2} \mathrm{PO}_{4}$ - cálcio - micela.

0 magnésio também reage com o fosfato adicionado aos solos formando fosfato dimagnésico trihidratado $\left(\mathrm{MgHPO}_{4} \cdot 3 \mathrm{H}_{2} \mathrm{O}\right)$ e/ou fosfato trimagnésico $\left(\mathrm{Mg}_{3}\left(\mathrm{PO}_{4}\right)_{2}\right)$. Por dissolução o fosfato dimagnésico forma o fosfato trimagnésico, menos solūvel em à gua. (RACZ e SOPER, 1967).

Quatro solos contendo diferentes teores de cálcio e magnésio foram tratados com $\mathrm{K}_{2} \mathrm{HPO}_{4}$ e $\mathrm{KH}_{2} \mathrm{PO}_{4}$ e incubados por vārios meses (STRONG e RACZ, 1970). Constatou-se a formação de seis diferentes 
fosfatos de cālcio e de magnésio: fosfato bicálcico bihidratado $\left(\mathrm{CaHPO}_{4} \cdot 2 \mathrm{H}_{2} \mathrm{O}\right)$, fosfato octocálcico $\left(\mathrm{Ca}_{4} \mathrm{H}\left(\mathrm{PO}_{4}\right)_{3} \cdot 3 \mathrm{H}_{2} \mathrm{O}\right)$, um fosfato de cálcio $\left(\mathrm{Ca}_{4} \mathrm{P}_{2} \mathrm{O}_{9}\right)$, fosfato de cālcio e magnésio trihidratado $\left(\mathrm{MgHPO}_{4} \cdot 3 \mathrm{H}_{2} \mathrm{O}\right)$ e fosfato trimagnésico com 22 moléculas de āgua $-\mathrm{Mg}_{3}\left(\mathrm{PO}_{4}\right)_{2} \cdot 22 \mathrm{H}_{2} \mathrm{O}$. A conversão das formas mais solūveis foi mais lenta quando se usou o $\mathrm{KH}_{2} \mathrm{PO}_{4}$.

De acordo com LINDSAY et alii (1962) o fosfato aplicado em solos com alto teor de cálcio e em solos alcalinos precipita-se usual mente como fosfato bicālcico bihidratado e/ou fosfato octocálcico. Segundo HUFFMAN (1962), a solubilidade em āgua destes compostos decresce na seguinte ordem: fosfato bicálcico hidratado, fosfato octocálcico e hidroxiapatita.

\subsubsection{Influência da matēria orgānica}

A influēncia dos resîduos orgānicos no fenōmeno da fixação é bastante controvertida. Acredita-se que certos produtos da decomposição da matéria orgânica tais como ācidos orgānicos e humus associamse com o ferro e alumīnio formando complexos; esta associação que resul ta na inativação dos ions ferro e aluminio reduz acentuadamente a fixação do fósforo inorgânico (BUCKMAN \& BRADY, 1968).

Estudos conduzidos por BHAT e BOYER (1968), em solos tropicais, revelaram uma diminuição na fixação de fosfato e aumento do fósforo isotopicamente trocāvel pela adição de matēria orgānica. Entretanto, a capacidade de fixação de fósforo era maior nos solos com maior teor de matéria orgānica original. 
RODRIGUES e SANCHEZ (1968) em experimentos de laboratōrio concluiram haver maior capacidade de fixação em solos com maior teor de matéria orgānica.

A matéria orgānica tem influēncia marcante na fixação de fosfatos e depende, em parte, do seu teor no solo e do seu estágio de mi neralização, o conhecimento da quantidade e do grau de intensidade desta fixação (SAUCHELLI, 1965).

LEAL (1971), encontrou correlação altamente significativa entre adsorção de fósforo e matéria orgânica.

TISDALE \& NELSON (1970) citando vārios trabalhos, mostraram algumas vantagens da matéria orgānica no aumento do fósforo disponī vel: na decomposição da matéria orgānica, ocorre despreendimento de dióxido de carbono que, com a àgua, forma o ácido carbōnico que pode decompor certos minerais primários e, ainda, os extratos de humus podem au mentar a solubilidade dos fosfatos.

FASSBENDER (1969) afirma que devido à presença de cargas eletropositivas na matéria orgānica $\mathrm{O}$ ion $\mathrm{H}_{2} \mathrm{PO}_{4}$ é por ela adsorvido.

AHENKORAH (1968), utilizando 17 solos de Ghana calculou correlações müttiplas entre a fixação de fosfatos e os fatores que a determinam. Este autor encontrou que para esses solos o carbono e o ferro são determinantes da fixação de acordo com a equação:

$$
Y=88,65+153 x_{C \text { org. }}+1,81 x_{\%} \mathrm{Fe}
$$


onde:

Y é a fixação de fōsforo em e.mg/lo0g de solo.

\subsubsection{Influência do $\mathrm{pH}$}

Entre os fatores envolvidos, $\mathrm{O} \mathrm{pH}$ do solo chega a ser tão importante que ē geralmente empregado para separar em dois grupos os processos de fixação do fósforo. A calagem presta-se muito bem para com provar o efeito do $\mathrm{pH}$ na disponibilidade desse elemento. MALAVOLTA et alii. (1965) lembram a possibilidade da elevação do pH acarretar um aumento no teor de fósforo disponivel de tal ordem que possa desaparecer, por um certo tempo, a necessidade de se aplicar fertilizantes fosfatados.

Estudos realizados em oito solos do cerrado da região do Triāngulo Mineiro por BRAGA E DEFELIPO (1972), demonstraram que a calagem alterou de maneira desuniforme os teores de fósforo disponivel.

Em estudo realizado por LOURENÇO (1973), em solos do Paranā, verificou-se que o calcārio aumentou a adsorção māxima de fósforo. No entanto VASCONCELOS (1973), em solos do cerrado, encontrou que a adsorção māxima decresceu com o aumento do pH inicial da suspensão, sendo que num dos solos voltou a aumentar após pH 7,0.

DE DATTA et alii (1971), trabalhando com três solos do Havai verificaram que o fósforo na solução aumentava com o pH até 5,8 pa ra um dos solos e até 6,6 para outros dois. Resultados obtidos por CABALA e FASSBENDER (1971), estudando oito solos ácidos da Bahia, 
evidenciaram que a calagem diminuiu o poder de fixação atē pH 5,8, havendo a partir daî aumento.

TOTH e BEAR (1947) estudando o fenōmeno de fixação de fōs foro em solos ācidos de New Jersei (USA) constataram quea prática da calagem resultou numa redução de $47 \%$ a $51 \%$ na retenção de fosfato.

CATANI \& PELLEGRINO (1957), estudando três solos de Bauru-SP, consideraram que para os solos ācidos e com teor médio a alto em ōxidos hidratados de ferro e alumīnio, a causa mais importante da fixação de fósforo ē a sua adsorção às partīculas coloidais do solo.

0 efeito da calagem sob a disponibilidade do fósforo do solo foi estudada por MELLO et alii. (1976), concluiram que sendo o pH um fator que influencia a fixação do fósforo, a calagem, por sua vez, resulta no aumento de disponibilidade do fósforo do solo por reduzir-1he a fixação e tambēm por permitir-1he a mineralização mais intensa.

FASSBENDER (1969), estudando a capacidade de fixação de fósforo em solos da América Central e sua relação com as características edāficas verificou que dentre as propriedades do solo como, teor de carbono, argila, hidrōxidos de ferro livres, alumīnio trocável e pH, o $\mathrm{pH}$ e o conteūdo de $\mathrm{Fe}_{2} \mathrm{O}_{3}$ são os fatores que mais afetam a fixação de fōs foro.

HSU (1964), estudando solos do Canadā, considerou o material amorfo como principal fator de fixação de fósforo. Observou que quando uma solução de fosfato permaneceu por um ano em contato com solos levemente àcidos surgiu no sistema uma nova fase formada por 
hidröxido fërrico o qual retinha a maior parte do fósforo fixado.

0 pH é um fator bastante considerado e discutido na fixação de fosfato. A maioria dos autores concorda que a fixação é maior em condições elevadas de acidez ou alcalinidade.

\subsubsection{Influência do alumīnio trocável}

Com respeito ao $\mathrm{Al}^{+3}$ trocāvel TAYLOR et alii (1975), observaram ser este ion muito ativo na precipitação de fosfato, embora REEVE \& SUMNER (1970), não tenham encontrado nenhuma relação entre a capacidade de fixação dos solos estudados e o teor de $A 1^{+3}$ trocável.

SA et alii (1968), investigaram a influência do aluminio trocāvel, argila, limo, matéria orgānica, superfície especīfica, etc.,na capacidade de retenção de fósforo de 16 unidades de solos na zona de Per nambuco e constataram a participação do aluminnio trocável na fixação do fosfato adicionado. A relação fósforo/aluminnio trocável cresceu em importância quando a concentração do alumīnio era prōxima ou maior do que 1,0 e.mg/ $100 \mathrm{~g}$ de solo.

FASSBENDER (1969) estudou a retenção e transformação de fosfatos em oito Latossolos da Amazônia do Brasil e verificou uma fixação de $2,68 \%$ a $51,6 \%$ do fosfato adicionado. Encontrou correlação signi ficativa entre a retenção do fósforo e os teores de alumīnio trocável $(r=0,716)$ e de matéria orgānica $(r=0,860)$.

A existēncia de correlação entre Al e $H$ trocáveis, percentagem de saturação de bases, percentagem de argila e a capacidade de 
fixação de fósforo foi confirmada por BRow et ali i (1978). O autor não encontrou, entretanto, correlação com o ferro.

PRIMO et alii (1973) estudando a fixação de fósforo oriun da de diferentes fertilizantes concluỉram que quanto maior a dose aplica da, maior era a percentagem de fósforo fixada e que nos primeiros dias apōs a aplicação $50 \%$ do fösforo aplicado encontrava-se na forma de fosfa to de alumĩnio e fosfato de cálcio.

GUTNIK et alii (1967), estudando solos derivados de cinzas vulcānicas, observaram mudanças no fenōmeno de fixação de fósforo de vido a variação do pH. Os autores encontraram correlação entre a quantị dade de fósforo fixado e o teor de alumīnio trocável.

DE (1961), afirma que o processo de fixação de fosfato pode ser devido à associação do fosfato com os minerais do solo ou à remoção do fosfato da solução pela formação de compostos relativamente in solūveis de aluminnio. Em meio alcalino a maior parte do aluminio tende a formar $\mathrm{Al}(\mathrm{OH})_{3}$ Ou, dependendo das condições, $\mathrm{AlPO}_{4}$, explicando dessa forma porque a fixação de fosfato diminui com o aumento da alcalinidade do meio.

SYERS et alij (1971), trabalhando com 15 solos representativos do Rio Grande do Sul, também verificaram uma estreita correlação $(r=0,84)$ entre o fósforo retido e o alumīnio trocável; entretanto, a remoção deste ion pouco contribuiu para a diminuição da retenção do fösforo. 
FRANKLIN \& RETSENAUER (1960), estudando 17 solos de Washington, constataram que a fixação de fósforo foi altamente correlacionada com o alumīnio trocável e com o alumīnio solūvel em ácido cîtrico $0,5 \mathrm{M}$.

0 fósforo forma complexos solūveis com muitos ions metálicos tais como, $\mathrm{K}, \mathrm{Na}, \mathrm{Ca}, \mathrm{Mg}, \mathrm{Al}, \mathrm{Fe}$ (SILLEN e MARTEL, 1964). Como tais ions ocorrem frequentemente na solução do solo, é possîvel que uma boa parte do fósforo presente seja complexado (LARSEN, 1967).

A presença de $\mathrm{Ca}, \mathrm{Fe}, \mathrm{Al}, \mathrm{Mg}, \mathrm{K}, \mathrm{H}$, OH e F constitui, independentemente da fase do solo em que se encontrem, uma ameaça constante para os ions fosfatos (LANDSAY \& MORENO, 1960). Coube a esses autores relacionar a atividade de cada um desses ions com a estabilidade dos respectivos compostos encontrados na fase sōlida. Para eles, o produto das reações que ocorrem poderā ser ou não precipitado segundo a concentração de tais ions na solução do solo. 
3. MATERIAIS E METODOS

3.1. Materiais

Foram utilizadas 100 amostras de horizontes superficiais de solo oriundas de vārios municípios do Estado de São Paulo. Essas amostras foram submetidas à anālise quîmica e granulométrica e, posteriormente ao teste de fixação de fosfato.

As amostras de solo foram cuidadosamente selecionadas de maneira a obter o maior grau de variabilidade possivel dentro das condições oferecidas.

3.2. Determinação das caracterîsticas fỉsicas e quîmicas

As caracterîsticas físicas e quîmicas dos solos utilizados no experimento estão contidas nos Quadros 1 e 2. 
Quadro i. Resultados da anālise granulométrica das 100 amostras de solos

\begin{tabular}{|c|c|c|c|c|}
\hline $\begin{array}{l}\text { Nọ da } \\
\text { amostra }\end{array}$ & $\begin{array}{c}\text { argila em ägua } \\
\%\end{array}$ & $\begin{array}{c}\text { argila em calgon } \\
\%\end{array}$ & $\begin{array}{c}\text { areia total } \\
\%\end{array}$ & $\begin{array}{c}1 \mathrm{imo} \\
\%\end{array}$ \\
\hline 1 & 14,7 & 20,9 & 58,3 & 20,8 \\
\hline 2 & 13,9 & 23,4 & 56,4 & 20,2 \\
\hline 3 & 2,4 & 39,4 & 18,7 & 41,9 \\
\hline 4 & 18,7 & 33,4 & 47,3 & 19,4 \\
\hline 5 & 5,8 & 12,8 & 81,9 & 5,3 \\
\hline 6 & 5,5 & 14,9 & 79,7 & 5,4 \\
\hline 7 & 16,4 & 56,9 & 21,0 & 22,1 \\
\hline 8 & 17,9 & 41,7 & 43,1 & 15,2 \\
\hline 9 & 9,0 & 17,8 & 74,7 & 7,5 \\
\hline 10 & 4,0 & 48,8 & 32,0 & 19,2 \\
\hline 11 & 10,9 & 17,7 & 44,8 & 37,5 \\
\hline 12 & 4,4 & 7,2 & 88,7 & 4,1 \\
\hline 13 & 20,1 & 43,6 & 42,4 & 14,0 \\
\hline 14 & 26,8 & 48,2 & 36,4 & 15,4 \\
\hline 15 & 9,2 & 18,4 & 74,0 & 7,6 \\
\hline 16 & 16,9 & 25,1 & 48,2 & 26,7 \\
\hline 17 & 13,6 & 20,0 & 32,1 & 47,9 \\
\hline 18 & 10,8 & 19,3 & 36,6 & 44,1 \\
\hline 19 & 4,7 & 10,8 & 47,4 & 41,8 \\
\hline 20 & 6,5 & 19,8 & 50,5 & 29,7 \\
\hline 27 & 15,9 & 47,7 & 36,6 & 15,7 \\
\hline 22 & 29,7 & 50,9 & 21,0 & 28,7 \\
\hline 23 & 0,2 & 36,2 & 47,7 & 22,1 \\
\hline 24 & 5,4 & 8,8 & 48,3 & 42,9 \\
\hline 25 & 23,9 & 32,8 & 41,2 & 26,0 \\
\hline 26 & 20,6 & 36,0 & 26,3 & 47,7 \\
\hline 27 & 8,8 & 20,0 & 51,0 & 29,0 \\
\hline 28 & 24,1 & 37,5 & 22,8 & 39,7 \\
\hline 29 & 22,7 & 39,4 & 27,3 & 33,3 \\
\hline
\end{tabular}


Quadro 1. Continuação

\begin{tabular}{|c|c|c|c|c|}
\hline $\begin{array}{l}\text { Nọ da } \\
\text { amostra }\end{array}$ & $\underset{\%}{\operatorname{argila}} \underset{\%}{\mathrm{em}}$ & $\underset{\%}{\operatorname{argila}} \underset{\%}{\text { em calgon }}$ & $\underset{\%}{\operatorname{areia} \text { total }}$ & $\underset{\%}{\operatorname{Timo}}$ \\
\hline 30 & 19,7 & 38,6 & 28,9 & 32,6 \\
\hline 31 & 21,5 & 43,1 & 43,1 & 13,8 \\
\hline 32 & 14,2 & 41,4 & 40,3 & 18,3 \\
\hline 33 & 20,2 & 42,6 & 45,2 & 12,2 \\
\hline 34 & 18,5 & 36,5 & 39,1 & 24,4 \\
\hline 35 & 8,4 & 23,5 & 68,2 & 8,3 \\
\hline 36 & 10,8 & 28,4 & 56,5 & 15,1 \\
\hline 37 & 2,0 & 4,4 & 86,8 & 8,8 \\
\hline 38 & 9,2 & 13,6 & 54,8 & 31,6 \\
\hline 39 & 5,8 & 10,2 & 69,8 & 20,0 \\
\hline 40 & 0,6 & 1,8 & 93,4 & 4,8 \\
\hline 41 & 20,8 & 32,9 & 39,8 & 27,3 \\
\hline 42 & 7,8 & 17,7 & 73,6 & 8,7 \\
\hline 43 & 4,7 & 14,5 & 76,7 & 8,8 \\
\hline 44 & 4,2 & 21,2 & 68,6 & 10,2 \\
\hline 45 & 19,5 & 41,2 & 41,9 & 16,9 \\
\hline 46 & 3,0 & 8,8 & 70,4 & 20,8 \\
\hline 47 & 14,0 & 38,8 & 46,6 & 14,6 \\
\hline 48 & 6,7 & 10,4 & 54,8 & 34,8 \\
\hline 49 & 27,2 & 42,9 & 43,9 & 13,2 \\
\hline 50 & 22,7 & 36,7 & 48,2 & 15,1 \\
\hline 51 & 25,4 & 39,2 & 48,6 & 12,2 \\
\hline 52 & 28,8 & 42,7 & 44,1 & 13,2 \\
\hline 53 & 25,4 & 36,2 & 52,1 & 11,7 \\
\hline 54 & 23,3 & 35,4 & 49,1 & 15,5 \\
\hline 55 & 3,4 & 7,0 & 73,1 & 19,9 \\
\hline 56 & 3,5 & 5,4 & 78,9 & 15,7 \\
\hline 57 & 2,4 & 7,0 & 77,7 & 15,3 \\
\hline 58 & 5,2 & 12,6 & 80,9 & 6,5 \\
\hline 59 & 9,8 & 21,9 & 74,7 & 3,4 \\
\hline
\end{tabular}


Quadro 1. Continuação

\begin{tabular}{|c|c|c|c|c|}
\hline $\begin{array}{l}\text { Nọ da } \\
\text { amostra }\end{array}$ & $\begin{array}{c}\text { argita em àgua } \\
\%\end{array}$ & $\begin{array}{c}\text { argila em calgon } \\
\%\end{array}$ & $\begin{array}{c}\text { areia total } \\
\%\end{array}$ & $\begin{array}{c}1 \mathrm{imo} \\
\%\end{array}$ \\
\hline 60 & 8,4 & 14,4 & 73,6 & 12,0 \\
\hline 61 & 7,2 & 16,8 & 66,2 & 17,0 \\
\hline 62 & 9,6 & 18,9 & 70,0 & 11,1 \\
\hline 63 & 9,7 & 17,0 & 69,5 & 13,5 \\
\hline 64 & 4,9 & 17,5 & 50,2 & 38,3 \\
\hline 65 & 7,0 & 11,4 & 82,5 & 6,1 \\
\hline 66 & 5,2 & 10,6 & 85,7 & 3,7 \\
\hline 67 & 5,4 & 11,4 & 81,7 & 6,9 \\
\hline 68 & 6,2 & 11,8 & 74,4 & 13,8 \\
\hline 69 & 4,9 & 7,4 & 64,6 & 28,0 \\
\hline 70 & 4,0 & 6,3 & 84,1 & 9,6 \\
\hline ו & 3,5 & 6,0 & 83,5 & 10,5 \\
\hline 72 & 5,4 & 8,8 & 82,6 & 8,6 \\
\hline 73 & 5,7 & 9,4 & 79,7 & 10,9 \\
\hline 74 & 4,4 & 50,3 & 17,9 & 31,8 \\
\hline 75 & 15,3 & 25,5 & 23,9 & 50,6 \\
\hline 76 & 14,1 & 27,9 & 40,8 & 37,3 \\
\hline 77 & 8,7 & 14,1 & 30,1 & 55,8 \\
\hline 78 & 12,0 & 23,9 & 30,4 & 45,7 \\
\hline 79 & 8,7 & 25,3 & 62,0 & 12,7 \\
\hline 80 & 5,7 & 12,3 & 84,9 & 2,8 \\
\hline 81 & 6,4 & 8,8 & 83,2 & 8,0 \\
\hline 82 & 4,2 & 7,5 & 87,8 & 4,7 \\
\hline 83 & 5,4 & 8,2 & 83,5 & 8,3 \\
\hline 84 & 6,4 & 10,6 & 82,5 & 6,9 \\
\hline 85 & 5,4 & 8,8 & 74,0 & 17,2 \\
\hline 86 & 4,6 & 7,3 & 84,0 & 8,7 \\
\hline
\end{tabular}


Quadro 1. Continuação

\begin{tabular}{ccccc}
\hline $\begin{array}{c}\text { No da } \\
\text { amostra }\end{array}$ & $\begin{array}{c}\text { argila em ägua } \\
\%\end{array}$ & $\begin{array}{c}\text { argila em calgon } \\
\%\end{array}$ & $\begin{array}{c}\text { areia total } \\
\%\end{array}$ & $\begin{array}{c}\text { Timo } \\
\%\end{array}$ \\
\hline & & & & \\
87 & 4,0 & 6,6 & 86,6 & 6,8 \\
88 & 5,3 & 9,2 & 79,6 & 11,2 \\
89 & 8,9 & 23,4 & 69,9 & 6,7 \\
90 & 14,0 & 25,4 & 60,0 & 14,6 \\
91 & 12,5 & 43,3 & 38,2 & 18,5 \\
92 & 17,1 & 51,4 & 26,6 & 22,0 \\
93 & 12,7 & 35,1 & 32,9 & 32,0 \\
94 & 22,2 & 65,9 & 13,2 & 20,9 \\
95 & 25,5 & 77,4 & 12,8 & 19,8 \\
96 & 30,3 & 70,4 & 10,3 & 19,3 \\
97 & 24,4 & 50,3 & 18,8 & 30,9 \\
98 & 8,0 & 13,2 & 68,5 & 18,3 \\
99 & 6,9 & 12,2 & 51,9 & 35,9 \\
100 & 9,1 & 15,2 & 39,7 & 45,7 \\
& & & & \\
\hline
\end{tabular}




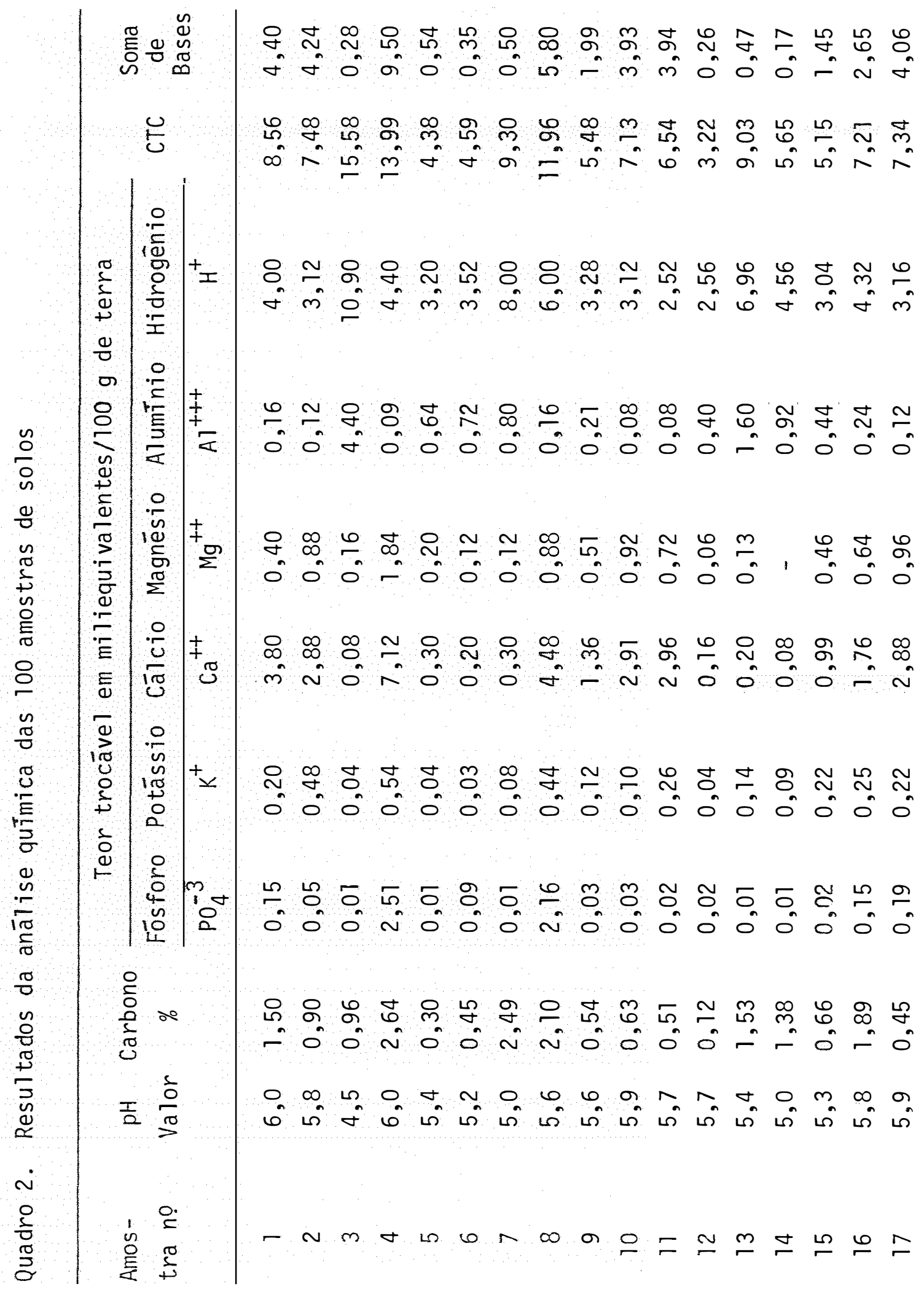




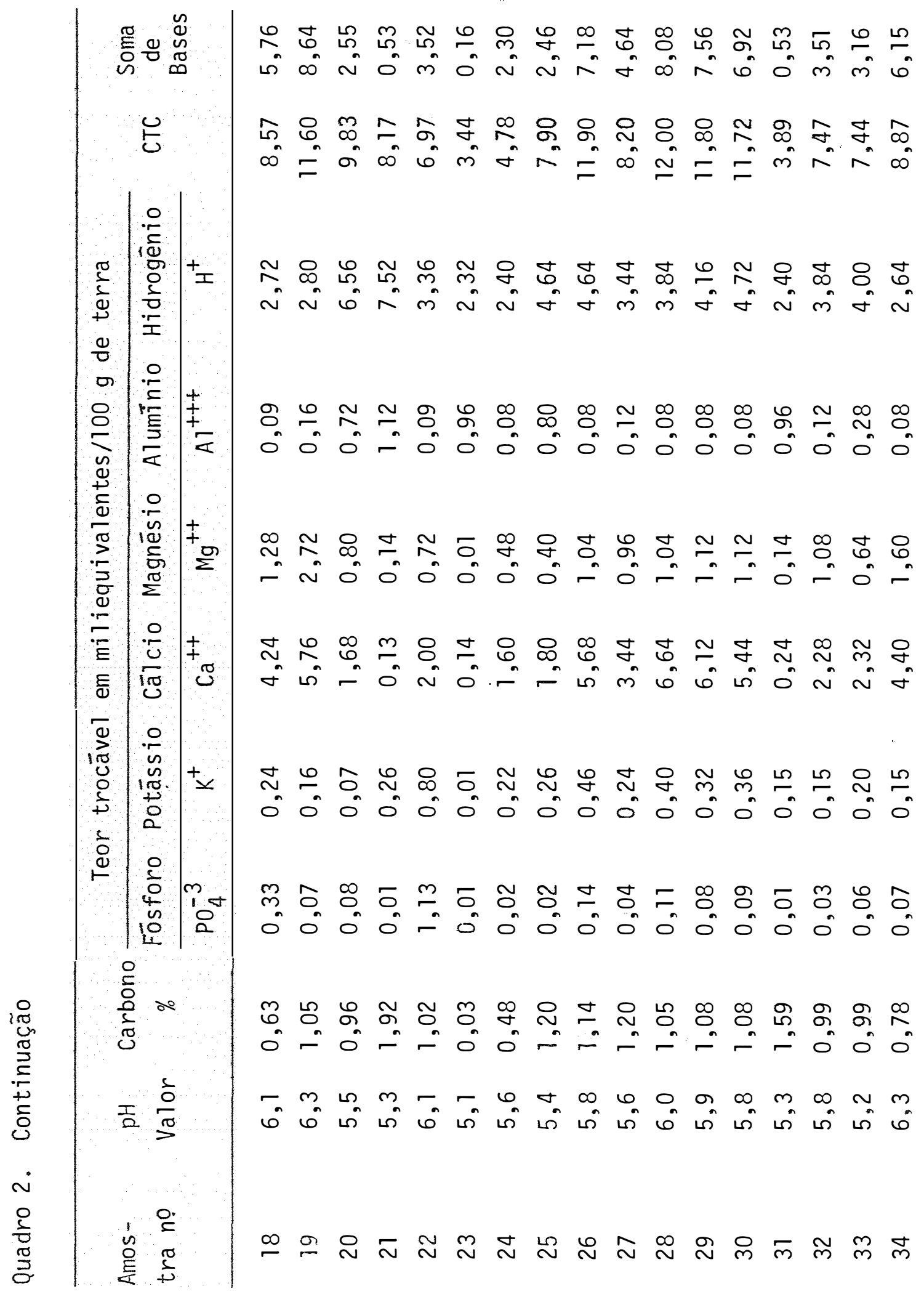




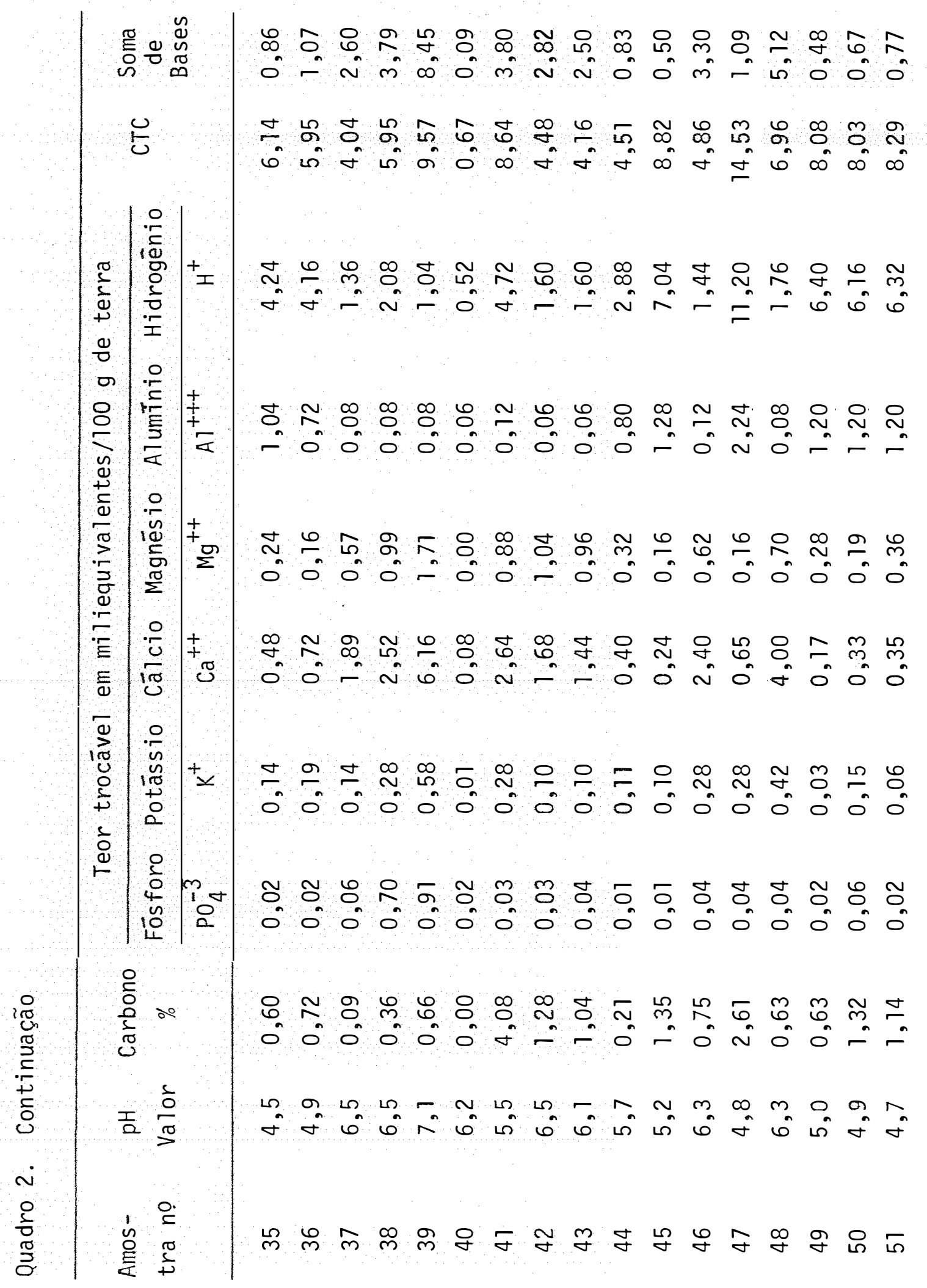




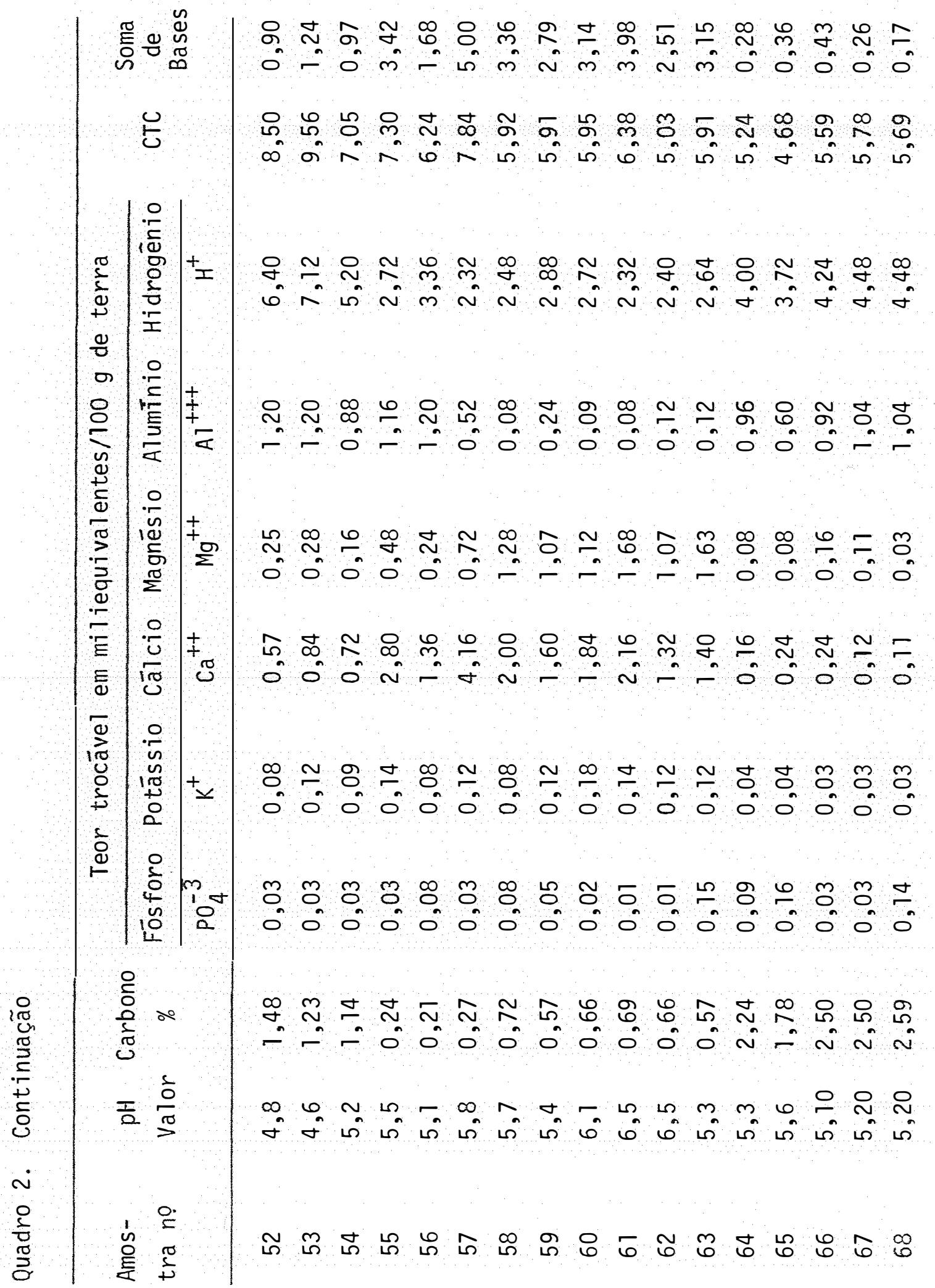




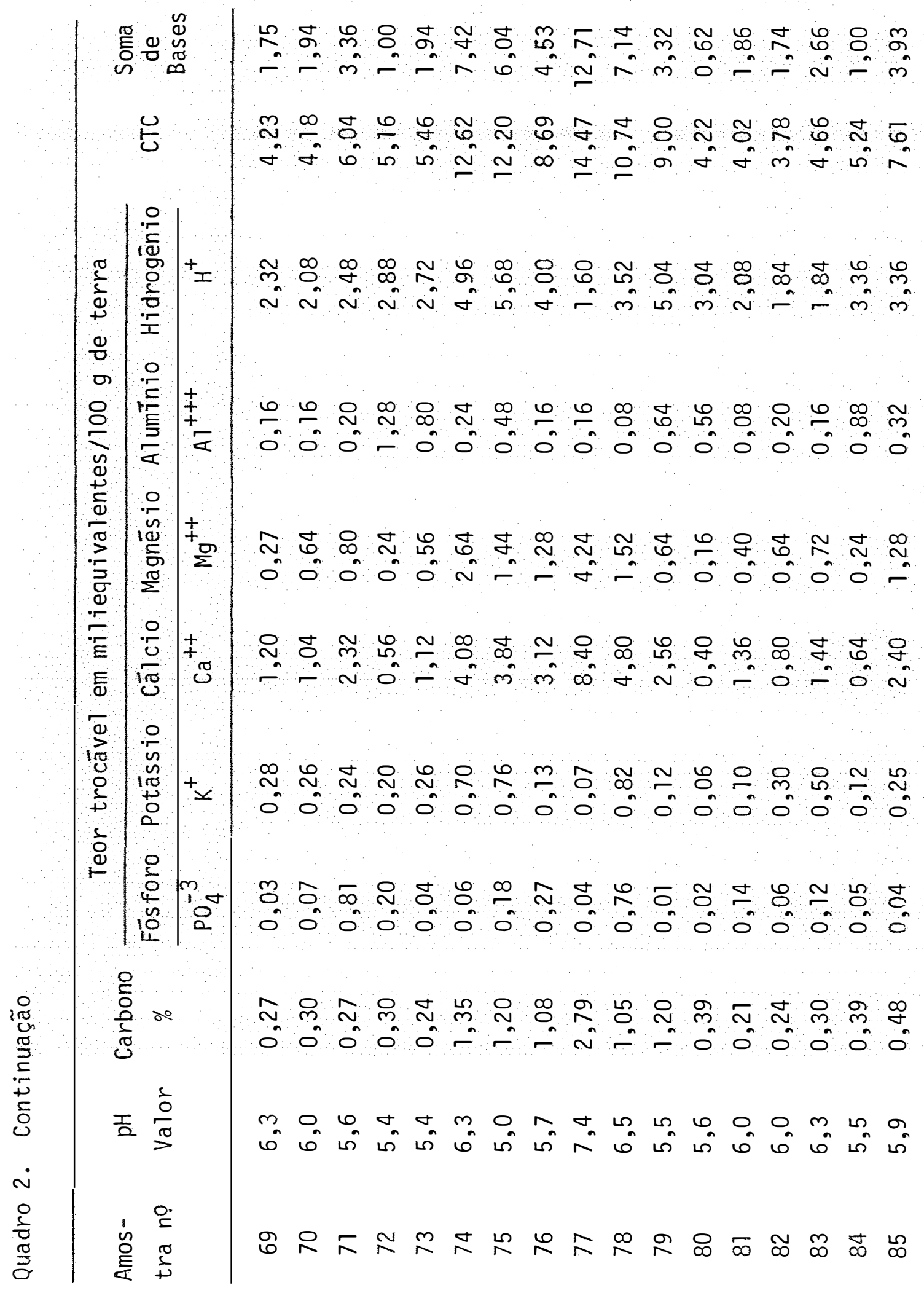




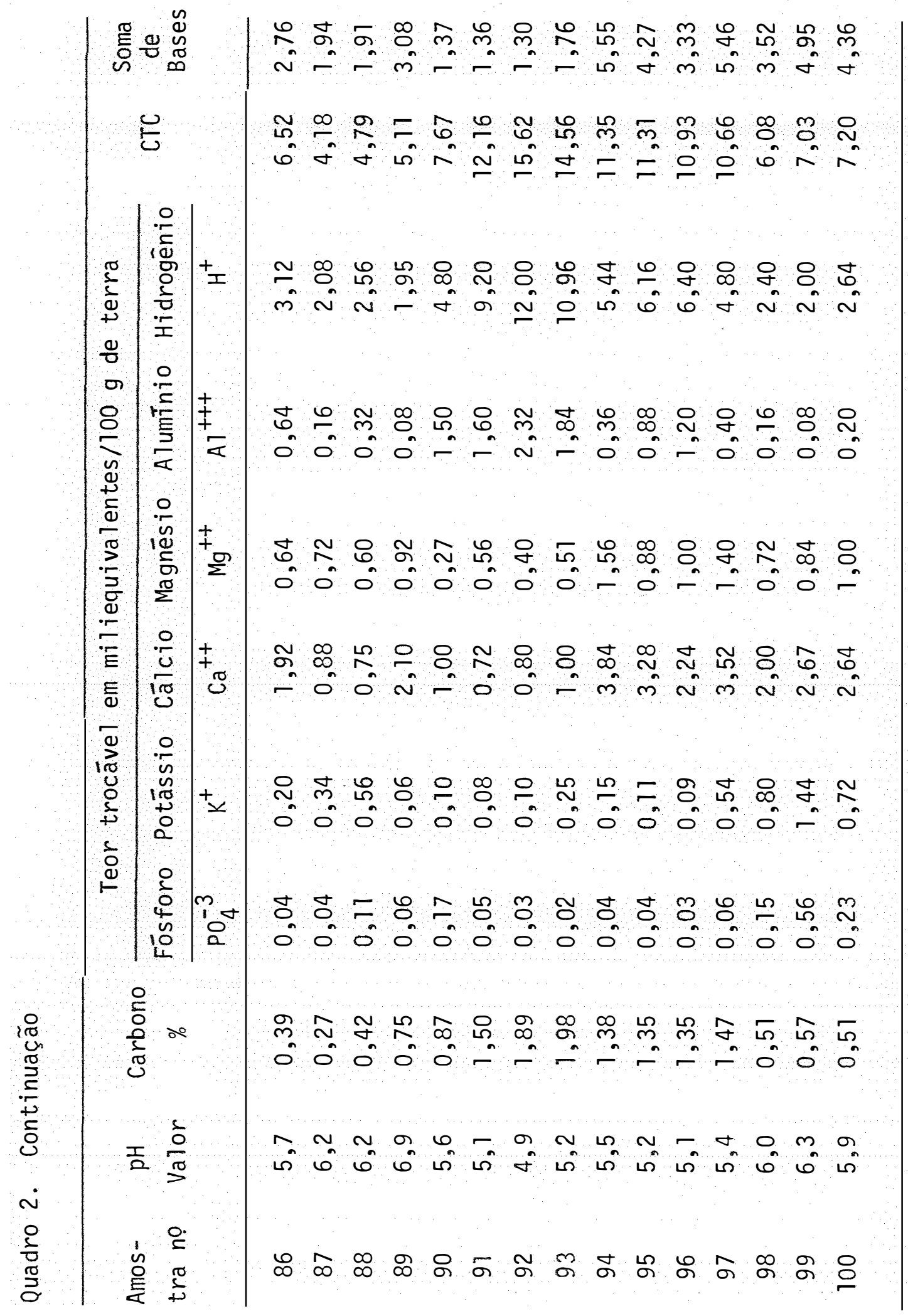


Os métodos analiticos empregados foram os seguintes.

\subsubsection{Caracterização física}

A anālise granulométrica foi executada seguindo o Método da Pipeta, MARCOS (1972). A dispersão foi feita com calgon (hexametafosfato de sōdio) a $5 \%$.

Determinou-se a porcentagem de argila em āgua e com dispersante, areia total e limo.

Os resultados da anālise granulomētrica das 100 amostras de solos encontram-se no quadro 1.

\subsubsection{Caracterização quîmica}

\subsubsection{Determinação do $\mathrm{pH}$}

A determinação do pH em āgua foi feita eletrometricamen te utilizando suspensão de solo em água, na proporção solo-āgua de 1:2.

3.2.2.2. Determinação do alumīnio trocāvel

$\mathrm{Na}$ determinação do alumīnio trocāvel usou-se como extrator o cloreto de potássio, $1 \mathrm{~N}$, e titulou-se com hidróxido de sōdio usando-se como indicador solução de fenolftaleina. 


\subsubsection{Determinação do carbono}

Determinou-se o carbono fazendo-se a oxidação da matēria orgānica com dicromato de potássio e titulando-se o excesso de oxidante com a solução de $\mathrm{FeSO}_{4} \cdot 7 \mathrm{H}_{2} \mathrm{O}$.

3.2.2.4. Determinação do fósforo solūvel em ācido sulfūrico $0,05 \mathrm{~N}$

Determinou-se o fósforo pela complexo fosfo-sulfomolíbdi co, usando como redutor cloreto estanhoso e efetuando-se a leitura em fil tro de 660 milimicrons.

3.2.2.5. Determinação do potāssio trocāvel do solo por fotometria de chama

0 potássio foi extraīdo usando $\mathrm{HNO}_{3} 0,05 \mathrm{~N}$. Ao extrato foi adicionado solução de fenolftaleina a $1 \%$ e efetuada a neutralização com $\mathrm{NH}_{4} \mathrm{OH}$ atē a viragem do indicador. 0 teor foi avaliado por fotometria de chama.

3.2.2.6. Determinação do cālcio e do magnésio trocáveis no solo

O cárcio e o magnésio foram determinados pelo método do EDTA (ācido etileno diamino tetraacético). Para o cálcio o indicador foi o metalo crōmico calgon. 
Para o cálcio junto com o magnésio o indicador foi o eriocromo preto $T$.

Os resultados da anālise quĩmica das 100 amostras de solo encontram-se no Quadro 2.

\subsection{Determinação da capacidade de fixação de fosfato pelo solo}

3.3.1. Marcha de determinação

Transferiu-se $4 \mathrm{~g}$ de terra para frasco de Erlenmeyer de $250 \mathrm{ml}$ e adicionou-se $100 \mathrm{ml}$ da solução aquosa $0,001 \mathrm{~N}$ em $\mathrm{PO}_{4}^{-3}$ proveniente do $\mathrm{KH}_{2} \mathrm{PO}_{4}$. Arrolhou-se o vaso e agitou-se em agitador horizontal durante 15 minutos sendo então efetuada filtragem em papel filtro qualitativo.

Foram transferidas aliquotas de $2 \mathrm{ml}$ do extrato e da so-

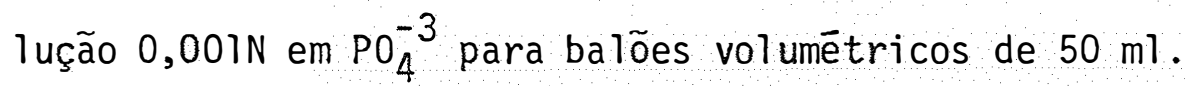

Adicionou-se a cada balão $1,5 \mathrm{ml}$ da solução de $\mathrm{H}_{2} \mathrm{SO}_{4} 5 \mathrm{~N}$, $2,5 \mathrm{ml}$ do reativo sulfomolibdico e $0,5 \mathrm{ml}$ da solução de cloreto estanhoso a $2 \%$, homogeneizando-se apōs a adição de cada reativo.

Completou-se o volume dos balões com āgua destilada, agitando-se e após 10 minutos procedeu-se a leitura em colorîmetro fotoelétrico, empregando-se filtro de 660 milimicrons.

3.3.2. Cálculo da porcentagem de fosfato fixada

A porcentagem de $\mathrm{PO}_{4}^{-3}$ fixada foi calculada pela seguinte fórmula: 
Fixação porcentual de $\mathrm{PO}_{4}^{-3}=100-\frac{100-L_{2}}{L_{1}}$

sendo:

$\mathrm{L}_{2}$ - nümero de e.mg de $\mathrm{PO}_{4}^{-3}$ em $100 \mathrm{ml}$ de solução $0,001 \mathrm{~N}$ em $\mathrm{PO}_{4}^{-3}$

$\mathrm{L}_{1}$ - nūmero de e.mg de $\mathrm{PO}_{4}^{-3}$ de solução que foi agitada com o solo.

Procurou-se obter correlações entre as quantidades de fos_fato fixada (em porcentagem) e as características quîmicas e físicas das mesmas.

Os resultados foram analizados estatisticamente através do emprego da anālise de regressão linear simples e de anālise de regressão linear mūltipla. 


\section{RESULTADOS E DISCUSSÃO}

Os resultados do teste de fixação de fosfatos das 100 amostras de solo são apresentados no Quadro 3.

As correlações lineares simples entre a porcentagem de fósforo fixado pelas 100 amostras de solo e as características fisica e quĩmica dos solos estudados são apresentados no Quadro 4. 
Quadro 3. Resultados do ensaio de fixação de fosfato

\begin{tabular}{|c|c|c|}
\hline Amostra no & $\begin{array}{l}\text { Porcentagem de } \\
\text { fixação }\end{array}$ & $\begin{array}{c}\text { Porcentagem cal culada } \\
\text { por regressão }\end{array}$ \\
\hline 1 & 15,1 & 15,8 \\
\hline 2 & 22,6 & 21,8 \\
\hline 3 & 54,8 & 63,8 \\
\hline 4 & 30,3 & 28,9 \\
\hline 5 & 6,2 & 13,8 \\
\hline 6 & 13,0 & 15,5 \\
\hline 7 & 52,1 & 51,8 \\
\hline 8 & 34,9 & 36,3 \\
\hline 9 & 13,0 & 15,4 \\
\hline 10 & 62,3 & 48,2 \\
\hline 11 & 13,0 & 16,6 \\
\hline 12 & 4,8 & 6,9 \\
\hline 13 & 33,5 & 45,5 \\
\hline 14 & 32,8 & 46,4 \\
\hline 15 & 22,6 & 17,9 \\
\hline 16 & 14,4 & 19,9 \\
\hline 17 & 8,9 & 20,3 \\
\hline 18 & 10,9 & 19,9 \\
\hline 19 & 14,4 & 15,3 \\
\hline 20 & 14,4 & 21,0 \\
\hline 21 & 40,1 & 45,6 \\
\hline 22 & 47,6 & 48,3 \\
\hline
\end{tabular}


Quadro 3. Continuação

\begin{tabular}{|c|c|c|}
\hline Amostra nọ & $\begin{array}{l}\text { Porcentagem de } \\
\quad \text { fixação }\end{array}$ & $\begin{array}{c}\text { Porcentagem calculada } \\
\text { por regressão }\end{array}$ \\
\hline 23 & 43,8 & 39,4 \\
\hline 24 & 5,4 & 7,0 \\
\hline 25 & 30,3 & 32,3 \\
\hline 26 & 34,9 & 34,1 \\
\hline 27 & 24,6 & 17,6 \\
\hline 28 & 47,6 & 35,5 \\
\hline 29 & 47,9 & 37,8 \\
\hline 30 & 41,8 & 37,0 \\
\hline 31 & 45,2 & 41,3 \\
\hline 32 & 58,9 & 40,3 \\
\hline 33 & 36,9 & 40,8 \\
\hline 34 & 45,2 & 37,6 \\
\hline 35 & 23,3 & 25,8 \\
\hline 36 & 43,8 & 28,2 \\
\hline 37 & 2,9 & 4,2 \\
\hline 38 & 10,9 & 13,9 \\
\hline 39 & 10,9 & 12,7 \\
\hline 40 & 1,4 & 1,9 \\
\hline 41 & 17,8 & 20,3 \\
\hline 42 & 11,6 & 15,0 \\
\hline 43 & 6,2 & 12,0 \\
\hline 44 & 15,7 & 23,8 \\
\hline 45 & 34,2 & 41,9 \\
\hline 46 & 4,1 & 6,7 \\
\hline 47 & 34,9 & 47,4 \\
\hline
\end{tabular}


Quadro 3. Continuação

\begin{tabular}{|c|c|c|}
\hline Amostra nọ & $\begin{array}{l}\text { Porcentagem de } \\
\text { fixação }\end{array}$ & $\begin{array}{l}\text { Porcentagem cal culada } \\
\text { por regressão }\end{array}$ \\
\hline 48 & 4,8 & 8,9 \\
\hline 49 & 53,4 & 46,2 \\
\hline 50 & 35,6 & 37,2 \\
\hline 51 & 43,2 & 41,1 \\
\hline 52 & 45,9 & 43,0 \\
\hline 53 & 37,7 & 37,4 \\
\hline 54 & 39,7 & 34,7 \\
\hline 55 & 11,6 & 12,1 \\
\hline 56 & 15,7 & 9,9 \\
\hline 57 & 5,5 & 9,2 \\
\hline 58 & 14,4 & 12,8 \\
\hline 59 & 20,5 & 22,8 \\
\hline 60 & 24,7 & 14,3 \\
\hline 61 & 28,7 & 18,5 \\
\hline 62 & 20,5 & 18,8 \\
\hline 63 & 22,6 & 19,2 \\
\hline 64 & 10,2 & 7,1 \\
\hline 65 & 9,5 & 6,6 \\
\hline 66 & 4,1 & 5,3 \\
\hline 67 & 8,9 & 6,6 \\
\hline 68 & 7,5 & 6,4 \\
\hline 69 & 3,4 & 6,1 \\
\hline 70 & 2,1 & 6,2 \\
\hline 71 & 4,8 & 6,7 \\
\hline 72 & 75,7 & 13,5 \\
\hline 73 & 12,3 & 12,7 \\
\hline 74 & 56,8 & 54,2 \\
\hline
\end{tabular}


Quadro 3. Continuação

\begin{tabular}{|c|c|c|}
\hline Amostra $n$ Q & $\begin{array}{l}\text { Porcentagem de } \\
\text { fixaçẵo }\end{array}$ & $\begin{array}{l}\text { Porcentagem calculada } \\
\text { por regressão }\end{array}$ \\
\hline 75 & 26,0 & 26,9 \\
\hline 76 & 19,2 & 21,4 \\
\hline 77 & 15,7 & 17,9 \\
\hline 78 & 18,4 & 23,8 \\
\hline 79 & 29,4 & 26,1 \\
\hline 80 & 10,9 & 12,7 \\
\hline 81 & 2,7 & 8,4 \\
\hline 82 & 15,6 & 9,1 \\
\hline 83 & 15,8 & 9,7 \\
\hline 84 & 20,5 & 13,2 \\
\hline 85 & 19,9 & 13,7 \\
\hline 86 & 8,2 & 9,4 \\
\hline 87 & 4,1 & 6,8 \\
\hline 88 & 10,2 & 9,3 \\
\hline 89 & 15,7 & 22,2 \\
\hline 90 & 27,4 & 30,4 \\
\hline 91 & 55,5 & 46,8 \\
\hline 92 & 56,8 & 57,4 \\
\hline 93 & 58,2 & 38,0 \\
\hline 94 & 63,7 & 64,2 \\
\hline 95 & 65,7 & 68,7 \\
\hline 96 & 71,9 & 73,6 \\
\hline 97 & 47,9 & 50,2 \\
\hline 98 & 10,3 & 12,5 \\
\hline 99 & 8,9 & 11,4 \\
\hline 100 & 10,9 & 15,8 \\
\hline
\end{tabular}


Quadro 4. Correlação entre a porcentagem de fósforo fixado e as caracteristicas do solo consideradas

\begin{tabular}{lcc}
\hline $\begin{array}{l}\text { Característica } \\
\text { do solo }\end{array}$ & $\begin{array}{c}\text { Coeficiente de } \\
\text { correlação }\end{array}$ & Teste T \\
\hline pH & $-0,4215$ & $4,60 * *$ \\
\%. de carbono & 0,3122 & $3,25 * *$ \\
P trocāvel & $-0,0265$ & $0,26 \mathrm{~ns}$ \\
Ca trocāvel & 0,0692 & $0,68 \mathrm{~ns}$ \\
Mg trocāvel & 0,0448 & $0,44 \mathrm{~ns}$ \\
Al trocāvel & 0,3886 & $4,17 * *$ \\
C.T.C. & 0,5766 & $6,98 * *$ \\
Soma de bases & 0,0247 & $0,24 \mathrm{~ns}$ \\
Argịa em ägua & 0,6484 & $8,43 * *$ \\
Argila em calgon & 0,9000 & $20,44 * *$ \\
Areia total & $-0,7335$ & $10,78 * *$ \\
\hline & 0,1352 & \\
\hline
\end{tabular}


4.1. Influência do $\mathrm{pH}$ na porcentagem de fosfato fixado

Como pode ser visto no Quadro 4, foi encontrada correlação negativa entre 0 pH e a porcentagem de fósforo fixado pelas 100 amostras de solo estudadas, com significância à nível de $1 \%$ de probabilidade pelo Teste T. A medida que se eleva o pH das amostras utilizadas, diminui a capacidade de fixação de fosfato pelo solo. Isto pode ser devido ao maior teor de Fe e Al livres encontrados nos solos ácidos. Em faixas de pH mais elevadas participariam do fenômeno de fixação as partículas de argila e, finalmente em solos alcalinos, os fosfatos podem ser precipitados por cations divalentes como $\mathrm{Ca}^{++} \mathrm{e} \mathrm{Mg}^{++}$.

Trabalhos de MALAVOLTA et alii (1965), BRAGA e DEFELIPO (1972), TOTH e BEAR (1947), confirmam a influencia positiva do aumento do pH sobre a disponibilidade de fósforo no solo. Todos são unânimes em afirmar a importância da calagem, ou da elevação do $\mathrm{pH}$, na diminuição da fixação de fosfatos pelo solo.

\subsection{Influência da \% de carbono na porcentagem de fixação de fosfato}

Foi encontrada correlação positiva a nîvel de $1 \%$ de probabilidade pelo Teste $T$ entre a porcentagem de fixação de fosfato e a porcentagem de carbono das 100 amostras de solo.

Esses resultados estão de acordo com alguns autores como LEAL (1971), AHENKORAH (1968), RODRIGUES e SANCHEZ (1968) que concluiram que a matéria orgânica aumenta a capacidade de fixação de fósforo; outros autores, entretanto, evidenciam o efeito benéfico da matéria orgānica 
sobre o conteúdo de fósforo disponīve1; entre eles estão TISDALE e NELSON (1970) e BHAT e BOYER (1968). BUCKMAN \& BRADY (1968), seguindo essa ūit ti ma corrente, explica que a associação dos produtos da decomposição da matéria orgānica tais como ācidos orgānicos e humus com o ferro e alumīnio formando complexos, inativaria os últimos reduzindo acentuadamente a fixa ção do fósforo inorgānico. Por outro lado FASSBENDER (1969) afirma que devido à presença de cargas eletropositivas na matéria orgānica 0 ion $\mathrm{H}_{2} \mathrm{PO}_{4}$ ē por ela adsorvido.

Há, portanto, uma certa controvérsia entre os autores a respeito da influência da matēria orgānica sobre a fixação de fósforo pe10 solo.

\subsection{Influência do $P$ solūvel na capacidade de fixação de fosfatos}

Não foi encontrada correlação significativa entre o conteú do de $P$ trocável e a capacidade de fixação de fosfato. Pode ser considerado um efeito negativo, apesar de estatisticamente não significativo. Um maior conteúdo de $P$ inicial no solo poderia acarretar uma menor fixação.

\subsection{Influenncia do Ca e Mg trocáveis sobre a capacidade de fixação de} fosfatos

No caso do Ca e Mg não foi encontrada correlação significativa entre os seus respectivos teores no solo e a porcentagem de fixação de fosfatos, quando se considerou o efeito isolado dessas caracteristicas quĩmicas. Entretanto, autores como ALLISON (1943), CALVERT et alii 
(1960) RAGLAND e SEAY (1957), RACZ e SOPER (1970), evidenciaram a influēn cia do cālcio e do Mg na fixação de fosfatos devido a esses elementos for marem compostos de solubilidade variāvel com o fósforo.

Comparando-se os resultados da anālise quīmica das 100 amostras de solo (Quadro 2) com os resultados de fixação (Quadro 3) podese notar que algumas amostras de solo, apesar de apresentarem teores relativamente altos de $\mathrm{Ca}$ e $\mathrm{Mg}$ trocāveis não apresentam $\mathrm{pH}$ favorāvel para que haja precipitação do ion fosfato por aqueles cations. BRADFIELD et alii (1935) estabeleceram a faixa de $\mathrm{pH}$ na qual esse fenōmeno ocorre como sendo de 6,0 a 10 . Pode-se notar, pelos dados de pH apresentados no quadro 2, que os solos estudados são, na sua grande maioria, àcidos.

4.5. Influência do $\mathrm{Al}^{+3}$ trocāvel sobre a capacidade de fixação de fosfatos

Ao se considerar o efeito isolado do $\mathrm{Al}^{+3}$ trocāvel sobre a porcentagem de fosfato fixado pelas 100 amostras encontrou-se correlação positiva a nîvel de $1 \%$ de probabilidade pelo Teste $T$. Isto pode ser devido a formação de compostos relativamente insolūveis de fosfato de Alu minio. Autores como FASSBENDER (1969), FRANKLIN e RETSENAUER (1960) confirmam haver correlação significativa entre o teor de Al trocāvel e a capacidade de fixação de fosfatos pelo solo. DE (1961) salienta que em meio alcalino a maior parte do aluminio tende a formar $\mathrm{Al}(\mathrm{OH})_{3}$ ou dependendo das condições $\mathrm{AlPO}_{4}$, explicando dessa forma porque a fixação de fos fato diminui com o aumento da alcalinidade do meio. 
4.6. Influēncia da capacidade de troca de cations (C.T.C.) sobre a capacidade de fixação de fosfatos.

No presente trabalho a autora encontrou correlação positiva significativa a nivel de $1 \%$ de probabilidade entre a capacidade de fixação de fosfatos e a CTC do solo. Uma explicação desse fenōmeno seria o fato de que solos com maior CTC, apresentam maiores teores de argila e matéria orgānica, fatores que influem significativamente a capacidade de fixação de fosfatos.

4.7. Influência da soma de bases trocāveis na capacidade de fixação de fosfatos

Não foi encontrada correlação significativa entre soma de bases trocáveis e a capacidade de fixação de fosfatos.

4.8. Influência do teor de argila na capacidade de fixação de fosfatos

0 conteúdo de argila influenciou significativamente a capacidade de fixação de fosfatos pelo solo havendo correlação positiva a nível de $1 \%$ de probabilidade pelo Teste T. Resultados semelhantes foram obtidos por ANASTACIO (1968), JUO e FOX (1977), MELLO (1968).

Explicações a esse fenômeno são dadas por COLLEMAN salientando que a fixação de fosfatos é devida à troca aniōnica entre os ions fosfatos e as oxidrilas do capeamento de luceroxidas livres de ferro e aluminio dificilmente removiveis das argilas. 
Comparando-se os resultados da anālise granulomētrica das 100 amostras do solo (Quadro 1) com os resultados de fixação de fosfatos (Quadro 3) pode-se notar que alguns solos com alto teor de argila fixaram pouco fósforo; o contrārio tambēm ocorreu. HALL e BEKER (1971) salientam a importāncia do tipo de argila na fixação de fosfatos. COLE e JACKSON (1950) evidenciam que dentre os argilo-minerais, os do grupo da vermiculita parecem apresentar maior poder de fixação. Além disso, tambēm o pH tem influēncia no comportamento desses minerais. Esses fenōmenos poderiam explicar, até certo ponto, algumas discrepáncias nos resulta dos obtidos. E interessante salientar que no presente estudo utilizou-se apenas a porcentagem de argila contida em cada amostra.

4.9. Influēncia do teor de Areia Total na capacidade de fixação de fosfato

Como pode ser visto no quadro 40 teor de areia das amostras de solos estudados influenciou significativamente a capacidade de fixação de fosfato pelo solo. Foi encontrada correlação negativa a nîvel de $1 \%$ de probabilidade, resultado jā esperado, uma vez que apenas as frações mais finas do solo têm maior capacidade de fixação de fosfato. $\bar{A}$ medida que o teor de areia total se eleva diminui a fixação.

4.10. Influência do teor de limo na capacidade de fixação de fosfato

Não foi encontrada correlação entre a capacidade de fixação de fosfato e o teor de limo das amostras de solos, discordando de 
autores como MELLO (1968) que encontrou correlação entre essas caracterîsticas.

4.11. Correlação linear mūltipla entre a capacidade de fixação de fosfato e as caracteristicas do solo estudadas.

Alēm da anālise de regressão linear simples, na qual è verificado o efeito isolado de cada característica estudada sobre a fixação de fosfatos, os resultados foram submetidos também à anālise de regressão mūltipla pelo processo de BACKWARD ELIMINATION. Por esse método busca-se encontrar a melhor equação de regressão para a porcentagem de fosfato fixada e as demais variāveis consideradas, ou seja, na equação são incluidas apenas as variāveis que influem significativamente, a nīvel de $5 \%$ de probabilidade, na porcentagem de fixação de fosfato, dentro do contexto geral de todas as variáveis.

A tîtulo de posterior discussão é dada a ordem de eliminação das variāveis não incluîdas na equação, salientando-se que a primeira variāvel eliminada é a que menor efeito tem sobre o processo de fixação.

A ordem de eliminação foi a seguinte: areia total, C.T.C. soma de bases, argila em àgua, pH, Ca, 1 imo, fósforo trocāvel.

A anālise de variância final é apresentada no Quadro 5. 
Quadro 5. Anālise de variāncia final de regressão linear mūltipla para $Y$ (\% de fósforo fixado) e as variāveis selecionadas $X_{2}(\%$ de carbono $) \mathrm{X}_{4}\left(\mathrm{Mg}^{++}\right.$trocāvel $)$e $\mathrm{X}_{5}(\mathrm{~A})^{+3}$ trocāvel $)$ e $\mathrm{X}_{9}(\%$ de ar gila)

\begin{tabular}{lcccc}
$\begin{array}{l}\text { Causas de } \\
\text { variação }\end{array}$ & G.L. & S.Q. & Q.M. & F \\
\hline Regressão & 4 & 27468,09043 & 6867,022609 & $131,515^{* *}$ \\
Desvio regressão & 95 & 4922,932407 & 51,82034114 & \\
Total & 99 & 32391,0228 & & \\
\hline
\end{tabular}

A equação de regressão linear mūltipla obtida por esse pro cesso foi a seguinte:

$$
Y=-2,266-3,484+3,514 \mathrm{Mg}+5,559+1,005 \% \text { argila calgon }
$$

onde:

$Y=$ porcentagem de fosfato fixado pela amostra de solo considerado.

0 coeficiente de determinação foi de $84,8 \%$. Como pode ser visto as variāveis selecionadas foram: porcentagem de carbono, teor de $\mathrm{Al}^{+3}$ trocāvel, teor de $\mathrm{Mg}^{+2}$ trocāvel e porcentagem de argila em calagem.

0 teor de $\mathrm{Mg}^{+2}$ trocāvel aparece agora como uma das variāveis que unida as demais selecionadas melhor exprime a capacidade de fixação de fosfato pelo solo; entretanto, quando se considerou o efeito 
isolado desse elemento não houve correlação significativa com a porcentagem de fosfato fixado. Isto evidencia a influência conjunta de vārias características do solo, interdependentes, sobre o processo de fixação.

Por outro lado, caracteristicas que isoladamente tiveram efeito significativo, quando analizadas em conjunto, não exprimiram o mes mo efeito.

Com respeito a ordem de eliminação pode-se observar que a porcentagem de areia total foi a caracteristica de menor efeito sobre a capacidade de fixação de fosfato. 0 teor de fósforo trocāvel foi a ūltima caracterīstica a ser eliminada no processo de fixação quando comparada com as demais caracteristicas anteriormente eliminadas.

Analizando-se ainda a equação de regressão linear mūltipla obtida nota-se que a variāvel de maior influência no resultado obtido com a utilização dessa equação è a porcentagem de argila, em outras palavras, essa foi a variāvel que mais influenciou o processo.

A partir dessa equação de fixação, foram obtidos valores estimados da porcentagem de fosfato fixado pelas 100 amostras de solo uti lizadas. Esses valores foram anexados ao Quadro 3 com a finalidade de fa cilitar a comparação com os resultados de fixação obtidos em laboratōrio.

Pode-se observar neste Quadro que os valores estimados apresentam razoável aproximação aos valores observados, o que permite dizer que as características do solo, porcentagem de carbono, teor de $\mathrm{Mg}^{+2}$ trocāvel, teor de $\mathrm{Al}^{+3}$ trocāvel e a porcentagem de argila são caracterīsticas razoavelmente seguras pará se estimar a capacidade de fixação de fosfatos para os solos utilizados. 
5. CONCLUSÕES

Para as condições em que foi realizado este trabalho e com base na anālise estatîstica dos resultados experimentais conclui-se que:

1. Com base na anālise de regressão linear simples as caracteristicas do solo que afetaram significativamente a capacidade de fixação de fosfato dos solos do Estado de São Paulo foram: \% de carbono, teor de $\mathrm{Al}^{+3}$ trocāvel, CTC, \% de argila, pH e \% de areia.

2. Com base na anālise de regressão linear mūltipla as caracteristicas que ma is influenciaram a capacidade de fixação de fosfato dos solos do Estado de São Paulo foram: \% de carbono, $\mathrm{Mg}^{+2}$ trocável, $\mathrm{Al}^{+3}$ trocāvel e \% de argila.

3. A equação que melhor exprime o fenômeno de fixação de fosfatos para sclos do Estado de São Pauĩo pode ser assim expressa: 


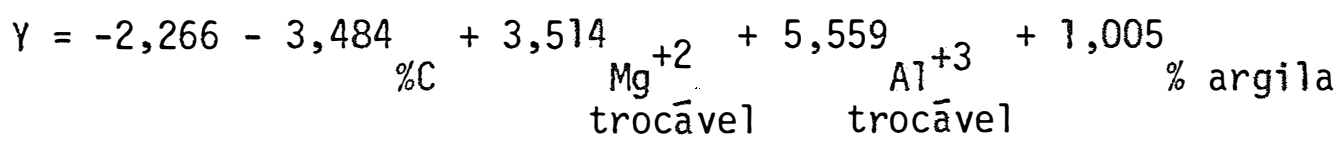

4. Em estudos relacionados com fixação de fosfatos pelo so10 é interessante levar-se em consideração o efeito conjunto das caracteristicas físicas e quimicas do solo sobre o processo. 
SUMMARY

A laboratory experiment was done to verify the effect of soil chemical and physical characteristics on the phosphate fixing capacity of soils occurring in the State of São Paulo.

One hundred samples collected from various localities were at first characterized chemically and their particle size distribution determined. They were then tested as to their phosphate fixing capacities.

The results obtained were statistically analyzed by means of both linear simple and multiple correlation. The following conclusions could be drawn:

1. Simples linear regression analysis indicated that $\% \mathrm{C}$, exchangeable $A 1^{+3}$, CEC, clay $\%, p H$ and sand $\%$ were the soil characteristics which significantly affected phosphate fixing capacity of Säo Paulo State Soils.

2. Multiple linear regression analysis indicated that $\% \mathrm{C}$, exchangeable $\mathrm{Mg}^{+2}$, exchangeable $\mathrm{Al}^{+3}$ and clay $\%$ were 
the soil characteristics which significantly affected phosphate fixing capacity of São PauTo State Soils.

3. Phosphate fixing phonomena as it occurs in the soils of São Paulo can be best described by the following equation:

$$
Y=-2.266-3.484 \underset{\% C}{3}+\begin{array}{ll}
\begin{array}{l}
\mathrm{Mg} \\
\text { exch. }
\end{array} & \begin{array}{l}
\mathrm{Al} \\
\text { exch. }
\end{array}
\end{array}
$$

4. Phosphate fixation in the soil is affected by the combined effects of both soil chemical and physica? characteristics. 


\section{LITERATURA CITADA}

AHENKORAH, Y., 1968. Phosphorus retention capacities of some cacaogrowing soils in Chana and their relationships with soil properties. Soil Science, Baltimore, 105(1):24-30.

ALLISON, L.E., 1943. The trend of phosphate adsorption by inorganic colloids from certain Indiana soils. Soil Science, Baltimore, 55: 333-342.

ANASTACIO, M. de L.A., 1968. Fixação de fósforo nos solos brasileiros. Boletim técnico da Equipe de Pedologia e Fertilidade do Solo, Rio de Janeiro, n. 4, $14 \mathrm{p}$.

BASS, G.B. e H.D. SHIELING, 1950. Method for determining reiative phosphate-fixing capacity of acid soils. Soil science, Baltimore, $69: 269-280$. 
BRADFIELD, R.; G. SCARSETH e J.G. STEELE, 1935. Factors affecting the retention of phosphate by clays. In: 3. International Congress of Soil Science, Oxford, v.l. p.74-75.

BRAGA, J.M. e B.V. DEFELIPO, 1972. Relações entre formas de fósforo dis ponível e material vegetal em solos sob vegetação de cerrado. I. Trabalho de Laboratório. Revista Ceres, Viçosa, 19(102):124-126.

BROWN, H.G. e H. LOEWENSTEIN, 1978. Relationship of soil properties to P-fixing capacity of soils in Northern Idaho. Communications. in Soil Science and Plant Analysis, New York, $9(7): 571-581$.

BUCKMAN, H.O. e N.C. BRADY, 1967. Natureza e propriedades dos solos. Trad. A.B.N. Figueiredo. Rio de Janeiro, USAID, 594p.

CABALLA, R.P. e H.W. FASSBENDER, 1971. Efecto del encanado en las formas y disponibilidad de fosfatos en suelos de la región cacaotera, Bahia, Brasil. Turrialba, 21:38-46.

CALVERT, D.V.; H.F. MASSEY e W.A. SEAY, 1960. The effect of exchangeable calcium on the retention of phosphorus by clay fractions of soils of the Memphis Catena. Proceedings of Soir Science Society of America, Madison, 24:333-335. 
CATANI, R.A., 1947. Contribuição ao estudo dos fosfatos, sua dosagem, ex tração e distribuição nos solos do Estado de São Paulo. Piracicaba, ESALQ/USP, 65p (Tese de doutoramento).

CATANi, R.A. e D. PELLEgRino, 1957. A fixação de fósforo em alguns solos do Estado de São Paulo, estudada com o auxīlio do fósforo radioativo ${ }^{32} \mathrm{P}_{15}$. Revista de Agricultura, Piracicaba, 32(4):237-252.

CATANI, R.A. e D. PELEGRINo, 1960. Avaliação da capacidade de fixação de fósforo pelo solo. Anais da Escola Superior de Agricultura "Luiz de Queiroz", Piracicaba, 17:19-28.

COLE, C.V. e M.L. JACKSON, 1950. Solubility equilibrium constant of dihidroxy-phosphate relating to a mechanism of phosphate fixation in soils. Proceedings of Soil Science Society of America, Madison, 15: 84-88.

COLEMAN, R., 1944. The mechanism of phosphate fixation by montmorillonitic and kaolinitic clays. Proceedings of Soil Science Society of America, Madison, 9: 72-78.

DE, S.K., 1961. Adsorption of phosphate ion by hydrogen derivative of Indian montmorillonite (Kashmir bendolite) Soil Science, Baltimore, 92: 117-119. 
DE DATTA, S.K.; R.L. FOX e G.D. SHERMAN, 1963. Availability of fertilizer phosphorus in three latossols of Hawai. Agronomy Journal, Madison, $55(4): 311-313$.

ELLIS Jr., R. e E. TRUOG, 1955. Phosphate fixation by montmorillonite. Proceedings of Soil Science Society of America, Madison, 19(4):451454.

FASSBENDER, H.W., 1966. La adsorciōn de fosfatos en suelos fuertemente àcidos y su evoluciōn usando la isoterma de Langmuir. Fitotecnia Latinoamericana, San José, $3(1 / 2): 203-216$.

FASSBENDER, H.W., 1969. Estudio del fósforo en suelos de América Central. IV. Capacidad de fijaciōn de fósforo y su relaciōn con caracterîsticas edáficas. Turrialba, 19:497-505.

FASSBENDER, H.W., 1969. Phosphorus fixation in tropical soils. Agridigest, Bruxelas, n. 18.

FASSBENDER, H.W., 1969. Retenciōn y transformaciōn de fosfatos en 8 latossolos de la Amazonia del Brasil. Fitotecnia Latinoamericana, San Josē, $\underline{6}(1): 115-126$.

FRANKLIN, W.T. E H.M. RETSENAUER, 1960. Chemical characteristics of soil related to phosphorus fixation and availability. Soil science, Ba]timore, 90:192-200. 
GUTNIK, V.; J. BALCAR; H. BEHRENS e E. ACEVEDO, 1967. Influencia de 1 pH sobre la fijaciōn del fósforo en suelos derivados de cenizas volcānicas. Agricultura Tecnica, Santiago de Chile, 27(4):141-143.

HALL, J.K. e D.E. BAKER, 1971. Phosphorus fixation by montmorillonitic and vermiculite clays as influenced by $\mathrm{pH}$ and soluble aluminum. Proceedings of Soil Science Society of America, Madison, 35:876-881.

HEMWALL, J.B., 1957. The fixation of phosphorus by soils. Advances in Agronomy, Palo Alto, 9:95-111.

HSU, P.H., 1964. Adsorption of phosphate by aluminum and iron in soils. Proceedings of Soil Science of America, Madison, 28(4):474-478.

HUFFMAN, E.0., 1962. Reaction of phosphate in soil; recent research by TVA. Proceedings of the Fertility Society of London, 75:5-35.

JUO, A.S.R. e R.L. FOX, 1977. Phosphate sorption characteristics of some Bench-Mark soils of West Africa. Soil Science Baltimore, 124(6): $370-376$.

KARDOS, L.T., 1969. Soil fixation of plant nutrients in: BEAR, F.E. ed. Chemistry of the soil. 2.ed. New York, Van Nostrand, p.369-394.

LARSEN, S., 1967. Soil phosphorus. Advances in Agronomy, Palo Alto, 19: $151-210$. 
LEAL, J.R., 1971. Adsorção de fosfato em latossolos sob cerrado. Rio de Janeiro, UFRRJ, 96p. (Tese de mestrado).

LINDSAY, W.L.; A.W. FRAZIER e H.F. STEPHENSON, 1962. Identification of reaction products from phosphate fertilizer in soil. Proceedings of Soil Science Society of America, Madison, 26:446-452.

LINDSAY, W.L. e E.C. MORENO, 1960. Phosphate phase equilibria in soils. Proceedings of Soil Science Society of America, Madison, 24(5):117182.

LOURENÇO, S., 1973. Adsorção e dessorção de fósforo em solos do estado do Paranā. Piracicaba, ESALQ/USP, 68p. (Tese de doutoramento).

MALAVOLTA, E.; 0.J. CROCCOMO; R.G. De ANDRADE; C. ALVIZURI; R. VENCOVSKY e L.M.M. FREITAS, 1965. Estudos sobre a fertilidade dos solos do cer rado. I. Efeito da calagem na disponibilidade do fósforo (Nota prēvia). Anais da Escola Superior de Agricultura "Luiz de Queiroz". Pi racicaba, 22:137-138.

MELLO, F.A.F., 1968. Capacidade de fixação de fosfato de alguns solos do municipio de Piracicaba. Revista de Agricultura, Piracicaba, 43: 23-27. 
MELLO, F.A.F. e F.J.A. CAVAlCANTI, 1976. 0 emprego do método de Mitscherlich na avaliação do efeito da calagem sobre a disponibilidade do fósforo do solo. Revista da Agricultura, Piracicaba, $51(1)$ :23-25.

MENDES, C.T., 1950. Adubações fosfatadas. Revista de Agricultura, Piracicaba, $25(1 / 2): 1-22$.

MILLAR, C.E., 1955. Soil Fertility. London, Chapman, 436p.

PRIMO, E.; J.M. SALA e R. SOLA, 1973. Estudio de la fijaciōn del fósforo biamōnico en un suelo calizo de la regiōn valenciana. Revista de Agroquímica y Tecnología de Alimentos, Valencia, 13(2):259-264.

RACZ, G.J. e R.J. SOPER, 1967. Reaction products of orthophosphates in soils containing varying amounts of calcium and magnesium. Canadian. Journal of Soil Science. Ottawa, 48:265-269.

RAGLAND, J.L. e W.A. SEAY, 1957. The effects of exchangeable calcium on the retention and fixation of phosphorus by clay fractions of soil. Proceedings of Soil Science Society of America, Madison, 21:261-264.

REEVE, N.G. e M.E. SUMMER, 1970. Effects of aluminum toxicity and phosphorus fixation on crop growth on 0xisols in Natal. Proceedings of Soil Science Society of America, Madison, 34(2):263-267. 
RODRIGUES, 0. e C. SANCHEZ, 1968. Fijación del fósforo por cuatro tipos de suelos de Sabana. Oriente Agropecuārio, Monagas, I (1):23-33.

SA JUNIOR, P.M.; I.F. GOMES e A.L. VASCONCELOS, 1968. Retenção de fōsforo em solos da zona de Mata de Pernambuco. Pesquisa Agropecuāria Brasileira, Rio de Janeiro, $\underline{3}: 183-188$.

SAUCHELLI, V., 1965. Phosphates in agriculture. New York, Reinhold, $277 p$.

SILLEN, L.G. e A.E. MARTEL, 1964. Stability constants of metal-iron complexes. Special Publication of Chemical Society, London, n.17.

STRONG, J. e G.J. RACZ, 1970. Reaction products of applied orthophosphate in some Manitoba soils as affected by soil calcium and magnesium content and time of incubation. Soil Science, Baltimore, 110:258-262.

SYERS, J.K.; J.T. EVANS; J.D.H. WILLIAMS, e J.T. MURDOCK, 1971. Phosphate sorption parameters of representative soils from Rio Grande do Sul, Brasil. Soil Science, Baltimore, 112(4):267-275.

TAYLOR, A.W. et alii, 1965. Precipitation of phosphate from ammonium phosphate solutions by iron and aluminum hydroxide. Proceedings of Soil Science, Society of America, Madison, 29:317-320. 
TISDALE, S.L. e W.L. NELSON, 1965. Soil Fertility and Fertilizers. New York, MacMillan, 430p.

TISDALE, S.L. e W.L. NELSON, 1970. Soil Fertility and Fertilizers. 2.ed. New York, MacMillan, 694p.

TOTH, S.J. e F. BEAR, 1947. Phosphorus adsorbing capacities of some New Jersey soils. Soil Science, Baltimore, 64:199-211.

VASCONCELOS, C.A., 1973. Contribuição para o estudo de fósforo em dois latossolos do Estado de Mato Grosso. Viçosa, UFV, i03p. (Tese de M.S.). 